\title{
Chatting On-line: An Assessment of Bilingualism and The Social Contexts of Language in Lebanon
}

\author{
Ghada M. Chehimi \\ Correspondence: Ghada M. Chehimi, Lebanese University, Faculty of Letters and Human Sciences, Beirut, Lebanon.
}

Received: June 24, 2021

Accepted: July 18, 2021

Online Published: July 22, 2021

doi:10.5430/elr.v10n3p8

URL: https://doi.org/10.5430/elr.v10n3p8

\begin{abstract}
This study aims to explore the Lebanese sociolinguistics as manifested in chatting, that is, to assess how a sample of Lebanese students use their languages skills while carrying an on-line conversation via chatting. The research will also investigate the variations governed by sociolinguistics branding the Lebanese chatting community. To carry out this study, a mix approach of quantitative and qualitative methodology is used. Indeed, the research will describe the participants' computer literacy and how this is interrelated to the choice of chatting language. The researcher uses two methods, formal interviews with selected chatters and a survey questionnaire that reflects both linguistic issues and computer and chatting literacy. Data analysis uses SPSS version 25 software and performed descriptively. Findings show that although having a multilingual society is considered a positive and uplifting certitude, this fact should not be taken for granted and languages must be directed properly. Students cannot be left without guidance to the use of any language.
\end{abstract}

Keywords: sociolinguistics, chatting on-line, flexibility, students, Lebanon

\section{Introduction}

\subsection{Background}

Human beings belong to a clever species of toolmakers and tool users. Some of the most remarkable human tools are the specific languages that particular groups of humans have developed and adapted for use in their daily lives (Henshilwood et al., 2002; Henshilwood \& Dubreuil, 2009). Over the years, the languages have evolved as conventional instruments for communication and, just as important for influence and control. Logical people prefer communication to be authentic and transparent, for them the use of a language should be like using a trolley that faithfully transports the thoughts and feelings of one person to another. (NG \& Bradac, 1993).

People use this tool (language) for better communication and to achieve appropriate understanding at all levels. There are many types of talks, although the boundaries of types of talks are always uncertain. According to Coupland (2000), 'the term 'small talk' has a recognized currency in several traditions of socio-linguistics, semantics and communication studies, and certainly in popular perceptions" (p. 1). According to Hudak \& Maynard (2011), citing Robinson (1972), this small talk can be labeled as 'gossip', 'chat' or 'time -out-talk'. What these labels point to is a range of supposedly minor, informal unimportant and non-serious modes of talk, linked to the general communicative function sometimes characterized as "talking to avoid other problems" (p. 2).

Lebanese researchers at the American University of Beirut, the Lebanese University, and the Lebanese American University increased their focus on linguistics in the last two decades. One reason for such renewed interest is the special formation of the Lebanese society and their preference in language use. After the war, Lebanese became more sophisticated in the way they manifest themselves for reasons of conserving their social class standards and to face the sudden attack of the Anglosaxon culture and language brought back with the Lebanese returning from the English-speaking nations. In fact, Marot (2018) asserts that "returnees come back with new cultural practices, consumption patterns, and professional know-how, enhancing family, clan and community solidarity with social networks that affect the Lebanese economy and society at large" (p. 5).

\subsection{The Internet and the World Wide Web}

The use of the World Wide Web (WWW) for educational purposes has overwhelmed many nations belonging to the third world category and continues to struggle (Sipe-Haesemeyer, 2005), especially if not ready to handle the knowledge demands that it provides. Hejase (2000) contends that "Efforts had increased recently to implement 
on-line education as a parallel move to Electronic Commerce. However, both applications are said to lack the interactivity much sought by the traditionalists, namely talking to a person rather than to the machine" (p. 1). Indeed, chatting is perceived to cover the stated gap and considered as an alternative mean knowing that chatters in the WWW use mostly English for their communication.

The fast implementation of Information and Communication Technology (ICT) in Lebanon helped overcome the setbacks due to a series of devastating wars and political unrest. Today, an observer can easily witness how Lebanese students had caught up taking the challenges offered to them very seriously. These challenges are manifested through technology, communication, and global learning through the Internet. However, the extent of the challenge is still widening due to the continuous developments that the Internet is undergoing. Seeking knowledge online is twinned with challenges in achieving Internet literacy. Chatting is a practice, although known to be based on having fun over the Internet, it also represents an educational tool if used adequately (Hejase, 2000, Chehimi, 2002).

The Internet, as an ICT tool, is credited in boosting to a large extent the evolution of humanity by enriching human-to-human interaction and communication. In fact, Christakis (2010) contends that "more complex types of external software-including the Internet-tend to involve communication and interaction, and thus they tend to be specifically social: they tend to involve the thoughts, feelings, and actions of many individuals, pooled in some way to make them accessible to individuals, including me" (para 3). Christakis, more specifically asserts, "The Internet thus facilitates an age-old tendency of the human mind to benefit from our tendency as a species to be homo dictyous (network man), an innate tendency we all have to connect with others and to be influenced by them. In this regard, the Internet is both mind-expanding and atavistic" (para 3).

Leiner et al. (1997) in their book 'The Internet Society' assert that "The Internet represents one of the most successful examples of the benefits of sustained investment and commitment to research and development of information infrastructure" (para 1). However, according to the Pew Research (2015), in their poll of general populations in 32 emerging and developing nations, they found that "Overall, a median of $64 \%$ across the 32 nations surveyed say that increasing internet use has a good influence on education, with only $18 \%$ saying it has a bad influence" (para 2). Moreover, "A median of 53\% across all the countries see the internet as a good influence on personal relationships, with a quarter saying the influence is bad" (para 3). These facts bring a positive motivation to approach chatting as an educational exercise. Chatting service allows real-time interaction between users across the globe over the Internet. "Chat is a two-way form of computer-mediated communication (CMC), a dialogue in real time as we keyboard or speak our words, an online conversation between two or more people" (Almeida d'Eça, 2002).

\subsection{Chatting and Education}

Hodson (1998) presents chatting as a text-based real-time communications tool. "Chatting enables two or more people, who are simultaneously connected to the Internet, to hold live, interactive conversations" (Laudon \& Laudon, 2010, p. 294). Chatting communication may "include exchanging information on a general chat applet, instant private messages, voice messages through the use of teleconferences, etc. Chat sessions can be ongoing and scheduled for a specific topic, time, and duration" (Hejase, Hejase, \& Khatib, 2013, pp. 241-242).

Traditionally, chatting per-se is an unconventional educational tool, it is associated with fun. Most people conduct chatting for entertainment. Pew Internet \& American Life surveys (PEW Research, 2004) reveal "that more than four in ten online Americans instant message (Para 3), ... Instant Message (IM) is used for playing games, watching TV and videos" (Para 35-36). Not only that, but also chatting has not a good reputation due to its potential of turning into chaos since chatters many times do not abide by the Net behavioral policies. Nevertheless, chatting has the potential to enable professionals assess their students' learning, that is, "Well-managed and focused synchronous chat sessions can provide powerful online learning experiences and add a dynamic dimension to a Web enhanced or online course" (Weber \& Lieberman, 2000). Furthermore, on the applied side, according to Almeida d'Eça (2003), "Integrating chat in EFL/ESL can be powerfully motivating and bring enormous excitement to what is generally a difficult process learning a language. Using chat means that the target language is learnt by interacting with people from the real world, in real time and using language of the real world, whether they are native or non-native speakers" (para 6).

\subsubsection{The Pedagogy of Chatting}

The last 25 years have witnessed multiple research efforts delineating the pedagogy of learning via the Internet. Olcott and Wright (1995) assert that "the responsibility for instructional quality and control, the improvement of learning and the aggregate effectiveness of distance education still rests on the faculty" (pp. 5-17). Dietz (2000; cited in Hejase, 2000) outlines "the basic instructor/student interactions in the traditional learning process which include 
pre-, post- and in-class materials, instructor and student questions, gauging student reactions and evaluating student comprehension" (p. 5). In fact, these instructor/student interactions are also found in E-learning. Moreover, the researchers Graziadei et al. (2000, p.2), Johnstone (1992) and Twigg (1992) confirm that technology with the appropriate changes in pedagogy, economies of scale, coupled with a shift to individualized, self-paced mastery learning, can make greater learning productivity possible. In fact, the aforementioned are congruent with the work of Bakia, Shear, Toyama, \& Lasseter (2012) who have found nine applications of online learning considered pathways to improved productivity as follows: "1) Broadening access in ways that dramatically reduce the cost of providing access to quality educational resources and experiences; 2) Engaging students in active learning with instructional materials and access to a wealth of resources; 3) Individualizing and differentiating instruction based on student performance; 4) Personalizing learning by building on student interests; 5) Making better use of teacher and student time by automating routine tasks and enabling teacher time to focus on high-value activities; 6) Increasing the rate of student learning by increasing motivation and helping students grasp concepts and demonstrate competency more efficiently; 7) Reducing school-based facilities costs; 8) Reducing salary costs by transferring some educational activities to computers, by increasing teacher-student ratios or by otherwise redesigning processes that allow for more effective use of teacher time; and 9) Realizing opportunities for economies of scale through reuse of materials and their large-scale distribution" (pp. vi-vii).

Along the same aforementioned applications, other researchers stress the learning curve improvement due to past experiences and success stories (Khoury et al., 2011; Clover, 2017; Gupta, 2017). Recently, Contact North (2020), reports that "Changes in society, student expectations, and technology were already motivating university and college faculty and instructors to rethink pedagogy and teaching methods before the pandemic. Canada has thousands of online courses and programs - there are 20,000 online college and university courses for credit in Ontario alone. Their number has been steadily growing since 1994" (p. 2).

According to e-learners (2021, para 21), chatting is applied as a tool for distance learning. Aljhani et al. (2018) contend that technology enabled e-learning to disseminate learning materials using an electronic layout via the internet. Moreover, e-learning capitalizes on the use of networks (local- or wide- area), for the delivery, interaction, and facilitation. Furthermore, Hejase and Chehimi (2020) assert that the "e-learning could also mean virtual teaching, online teaching, web-based training, distance teaching, and distributed learning" (p. 1). Chatting can be synchronous (simultaneously interaction in real-time) and asynchronous (interaction is delayed over time) (Thurlow, Lengel, \& Tomic, 2004; e-learners, 2021; Angelo State University, 2021). Moreover, e-learners (2021) define "Asynchronous learning to be often used in discussions by distance learning people" (para 8). Discussion Forums for example, are in asynchronous form and according to Krishnan \& Rogers (2015a, b), are "especially valuable from a social analytic standpoint as they are highly focused in their content and provide a candid view of the topic being discussed" (para 2). On the contrary Singh (n.d.) contends that "Net meeting chats are held in real time and allow having text-based, real-time synchronous discussions" (para 2). Therefore, they count as synchronous learning. In fact, there are almost immediate responses to posted comments between more than one person. Therefore, participants need to be logged onto the system real time. So, obviously the chatter needs to coordinate a time to meet online when he/she wants to use the program (Hodson, 1998, p. 2; Wilson, 1997, p. 2; Thurlow et al., 2004; Hrastinski, 2008; Singh, n.d.).

\subsubsection{Advantages of Chatting}

In education, chatting can facilitate the learning process (Weber \& Lieberman, 2003, p.1). In fact, Coman, Tîru, Mesesan-Schmitz, Stanciu, \& Bularca (2020, p. 2) contend that using asynchronous (e-mail and forums) and synchronous tools (chats and videoconferences) improve interaction with students. Moreover, it allows instructors/teachers to do online oral quizzes, considered a good evaluation method. Indeed, as asserted by Dumbaugh (2020), "Updating oral exams for the virtual classroom helps students improve their communication, conquer anxiety, solve problems quickly and think creatively" (Para 3). Furthermore, after the chat session, the conversation held could be recorded as a further reference so students can access them, a thing that does not usually happen in traditional schools. Weber \& Lieberman (2003) stress the fact that "Having chat logs publicly available allows students to review the discussions that transpired and gives those who were not present a chance to know what took place" (p. 2).

Instructors may supplement the chatting experience by inviting guest speakers (national and international figures) to chat sessions. Inviting experts enriches students' interaction and encourages sharing their information and benefit from professionals' opinions (Hejase, 2000; 2004). Feldstein (2009) asserts that sharing is a major benefit in online communities' interactions. Sharing includes mutual exchange of opinions, advice, experiences, and stories.

Usually, in distance learning programs, the supervision level is lower than in the traditional academic programs. The 
distant instructor and especially in credited courses where the student's academic honesty may be doubtful, seeks for finding a way to test the real performance of their students (Dr. Hassan Rkein, Online learning expert, personal communication, March 4, 2021). So, chatting, and since it is an online synchronous communication can allow more supervision for learners. Rovai (2000), for example, suggested several assessment methods for online courses including: proctored testing (via a delayed telephone conversation, online chat, or e-mail) and online discussion. Emphasizing the previously mentioned points, Robles and Braathen (2002) and Meyen et al. (2002) proposed synchronous chatting as an assessment method beside others.

\subsubsection{Disadvantages of Chatting}

Chatting as a synchronous approach is not free from disadvantages that may impact its probable pedagogical use. Pappas (2015) brings forward several issues including: Strictly technology-based ones. Actually, chatting will lose its efficacy if learners lack sufficient technical knowledge, computer skills, and ability to handle the various technologies involved in synchronous learning. In reality, Hejase et al. (2013) warn that the disadvantages may tremendously frustrate and discourage online learners. Chatting demands a high-speed internet connection though it is sensitive to local time barriers. Chatting requires careful planning including coordination of schedules and ensuring full participation. Finally, if learners lack social skills, chatting becomes a challenging task. Notwithstanding the presence of many technical problems for learners (line-disconnection; overloaded servers; and improper connections), chatting is still a feasible tool for learners including the Lebanese context where these problems are recurrently common.

Moreover, Coman et al. (2020, p. 2) call our attention to other obstacles to students' learning when using E-learning platforms (including synchronous chatting). These obstacles may include decreased students' motivation, delayed feedback or help, which is due to the unavailability of teachers at the time when students may need help, and the fact that students feel isolated due to lack of physical presence of classmates. Nevertheless, Russell (2021) contends that "classroom blogs provided an effective way to overcome feelings of frustration and isolation by providing an engaging and interactive forum for students" (Para 8). Indeed, Dickey (2004) reported that students who use blogs have been observed to have positive experiences and reduced feelings of isolation.

Thus, chatting cannot be a unique instruction method and learning should not totally depend on synchronous chatting. "It is true that it assists learners to get an answer in a minute than probe for hours to find it; however, it reduces the students' ability to depend on themselves to learn by doing and exploring, which is one of the learning objectives" (Hejase et al., 2013, p. 248).

\subsubsection{Chat Logistics}

According to Bagarukayo et al. (2014) and Bagarukayo \& van der Weide (2012), "learning is more effective with interactivity, collaboration and communication features in the Learning Management System (LMS). It is therefore important to provide these features to realize better performance and improvement in the learning process" (p. 271). However, not all institutions have the similar appropriate LMS in place to offer interactivity with chat logistics, a fact that leads institutions to adopt add-ons to supplement the current University Management System (UMS) in the student's learning endeavors. Exhibit 1 offers a summary of available, non-sophisticated, synchronous media to be used for chatting.

Exhibit 1. Chat logistics

\section{Chat Rooms}

Chat rooms exist for almost any subject imaginable. Internet Relay Chat (IRC), "is a multi-user synchronous communication facility that is available all over the world to people with access to the Internet" (Liu, 1999, p. 515). Conversations may be public or private. However, this can get chaotic when more than one speaker is involved. IRC is an outgrowth of Multiple-user Dimension or Multi-users Dungeons (MUDs) and other constructs e.g. MUD Object Oriented (MOOs), Multiple User Dimension (MUSE) and Multiple User Dimension Hallucination (MUSH). These programs are classified as role playing games that are currently used in education (Nolan and Weiss, 1999, p. 5: Internet and Neuage, 1999, p.5: Internet).

\section{Instant Messenger}

America On-Line's Instant Messenger (AIM), Facebook Instant Messenger and Yahoo Instant Messenger steer conversations into a particular area of discussion group no one else can enter the dialogue. Here the chat is more isolated and entry restricted.

According to Neuage (2000), Internet conversation following any of these schemes capitalizes on two paradigm 
shifts. Assuring an "electronic interactive conversational analysis" requires a crossover between print and conversation-based analysis and theorization. Firstly, "there is the shift from print to soft copy" (p. 33). Neuage (2004) adds, "Print relies on hierarchy and linearity, focusing on durability through both time and space, print texts must carefully direct the use-patterns of their 'remote' user, to ensure that their messages remain intact" (p. 33). On the other hand, Computer Mediated Communication (CMC) technologies have moved to create a direct and seemingly intimate contact for users, they do so using text messaging" (ibid). Computer interactivity using chat rooms can involve multiple conversations among many users. "Chatters can only read one line of text or one graphic can be observed at a time, with the next following rapidly in sequence and acting to de-focus what precedes it" (Neuage, 2004, p. 33). A second paradigm shift is on the notion of "discourse". With the Internet interactive environment there are further developments taking place. Shifts from e-mail and discussion groups to chat rooms and "Instant Messenger". In fact, Landow (1992) explains the shift as "abandoning conceptual systems founded upon ideas of center, margin, hierarchy, and linearity and replacing them with ones of multi-linearity, nodes, links, and textual networks" (p. 2).

Being on a global level the chat rooms and the communities need a common tool to be used by all people around the globe. This tool is the specific language a group chooses to use. This exploratory research will shed the light on chatting and the choice of language among the Lebanese youth (high school and college students).

\subsection{Bilingualism: An overview}

Merriam-Webster (n.d.) defines "Bilingualism" as "the ability to speak two languages and/or the frequent use (as by a community) of two languages" (Para 1). On the other hand, Moradi (2014) asserts that "a bilingual in everyday use is usually considered as an individual who can speak, interact, read or understand two languages equally well" (p. 107). Bilingualism is becoming popular around the globe and including all continents, "one in three people are bilingual or multilingual" (Wei, 2000). Given these facts, the study of bilingualism has undergone great deal of debate among scholars since the fifties (Grosjean, (1999; Shirley, 2016). The idea is to reach an agreement that could be a common base to which scholars could refer. Researchers though have presented a variety of points of view on how to address bilingualism. Kenji Hakuta (1990) presents several points of view about how bilingualism is identified and discussed. According to Hakuta (1990), the "Popular ones include coordinate vs. compound bilingualism (Weinreich 1953), early vs. late bilingualism (Lambert 1985), simultaneous vs. successive bilingualism (McLaughlin 1984), additive vs. subtractive bilingualism (Lambert 1975), and elite vs. folk bilingualism (Skutnabb-Kangas 1981)" (p. 2). Moreover, Hakuta asserts that the aforementioned distinctions have served a purpose in drawing attention to certain aspects of bilingualism. Exhibit 2 provides a summary for Hakuta's most important lesson to be learned from these distinctions.

Exhibit 2. Hakuta's Lessons learned

\begin{tabular}{|c|rl|}
\hline Aspect observed & \multicolumn{1}{c|}{ Type of Bilingualism } \\
\hline Reference to characteristics of individuals & $\bullet$ & Coordinate vs. compound \\
& $\bullet$ & Early vs. late \\
& $\bullet$ & Simultaneous vs. successive \\
\hline Reference to characteristics of groups & $\bullet$ & Additive vs. subtractive \\
& $\bullet$ & Elite vs. folk \\
\hline
\end{tabular}

Source: Hakuta, 2014, p. 2.

Being aware of the two classifications in Exhibit 2, one does not draw a clear understanding of the individual classifications per se. This is due to the fact that individuals as well as social groups' bilingualism has many dimensions on its own. As for individuals' bilingualism, the range can be from native-like control of two or more languages to possessing minimal communicative skills in a second or foreign language. For societal bilingualism, there is a range of possibilities. Countries such as the United States, France, Germany, Spain, Israel, Tunisia, Morocco, and Lebanon are characterized by groups of immigrants representing a broad mixture of languages spoken throughout the world, many of these groups having languages lost within three or more generations in a process of assimilation.

\subsubsection{Societal Bilingualism}

When two or more languages are spoken in a certain society, then societal bilingualism occur. Therefore, one can say that nearly all societies are bilingual. Though, the degree or form of bilingualism differentiates between these societies. 
Shirley (2016) contends that, "Societal bilingualism concerns language contact situations involving groups or communities within or between geographical locations, such as cities, regions or countries, which, in many cases, leads to individual bilingualism" (p. 16). According to Appel and Muysken (1987), bilingualism can be theoretically distinguished based on three situations: "(1) Two different groups speak two different languages, and each group is monolingual; a few bilingual individuals speaking both languages provide inter-group communication. Examples: Early former colonial countries, where colonizer spoke one language and the natives a local language. Recently, peace keeping forces and natives; (2) all people are bilingual. Examples in African countries and in India; and (3) often people have command of more than two languages. In societies of the third group one group is monolingual, and the other bilingual. In most cases this last group will form a minority, not numerically or statistically, but sociologically: It is a non-dominant or oppressed group. Greenland is an example" (pp. 2-3). The three forms are theoretical and may not exist in a pure form in the world. In fact, the linguistic situation of most countries is complex, with more than two groups and more than two languages involved. Therefore, different mixtures are much more common.

\subsubsection{Individual Bilingualism}

It was stated earlier that there are three popular forms for individual bilingualism. However, asserting who is a bilingual person is not a simple matter. Grosjean $(1999$, p. 1) asserts that there is continuous debate to label certain person a bilingual based on the extent of that person's command over the two languages. Many questions still need to be answered. Must the person have fluent oral and writing skills in both languages? Must a true bilingual be proficient in speaking and writing (productive) as well as in listening and reading (receptive) tasks? Which of the following components (vocabulary, pronunciation, syntax, and pragmatics) of the language are the criteria?

Since the early thirties, various definitions have been proposed. Bloomfield (1933) made the highest demands since according to him a bilingual should possess "native-like control of two or more languages" (p. 56). At the other extreme, Mackey (1962) and later Macnamara (1969) proposed that somebody is a bilingual if he/she has some second-language skills in one of the four modalities (Speaking, listening, writing, reading), in addition to his/her first language skills. This notion is also viewed by Grosjean (1999).

The term bilingual seems to be easy to be defined by many people: Being 'truly' bilingual means for them, being capable of speaking two languages (e.g. the predominant language of the area or country, where the person lives and an additional language) like a native speaker. But as there are various kinds of bilinguals and multi-linguals, it is necessary to develop a clear categorization. Having dealt with the definition of bilingualism, it deems necessary to define what is a 'Mother Tongue'?

\subsection{Mother Tongue and the Use of Two Languages}

This term has often been used by linguists in a technical sense to refer to an individual's first learned or primary language (Skutnabb-Kangas 1984, ch. 2). However, Lieberson (1969, p. 291) says that the United Nations adopted the definition of mother tongue as the "language usually spoken in the individual's home in his early childhood, although not necessarily used by him at present". Many researchers now prefer terms such as "first" or "second" or "community" language (Romaine, 1998, p. 19).

In one of its popular senses, the term 'mother tongue' evokes the notion of mothers as the passive repositories of languages, which they pass to their children. However, Saunders (1982, p. 152) found evidence that fathers could also take that role.

Other definitions worth looking at are the following: "Communication in the mother tongue is the ability to express and interpret concepts, thoughts, feelings, facts and opinions in both oral and written form (listening, speaking, reading, and writing), and to interact linguistically in an appropriate and creative way in a full range of societal and cultural contexts; in education and training, work, home and leisure" (European Community, 2006, p. L494/14).

Other definitions of the term 'mother tongue' have relied on competence (Romaine 1998, p. 22). A mother tongue would be the language one knows best, the one the individual identifies with, or a relative one if changed over the course of a lifetime.

\subsubsection{Bilingual Education}

It refers to "any school program in which more than one language is used in the curriculum to teach non-language academic subject matter or the language of schooling does not match the language of the home or community" (Bialystok, 2018).

Stroud (2002) presents four types of bilingual education programmes namely transitional, maintenance, enrichment, and restorative programs. Exhibit 3 provides brief details. 
Exhibit 3. Types of programs

\begin{tabular}{|l|l|}
\hline Programme & Description \\
\hline Transitional & $\begin{array}{l}\text { Aim for assimilation and social incorporation of language minorities in the national society } \\
\text { (Hornberger, 1991). This is done according to Stroud (2002) "through language shift. The } \\
\text { rationales include: the need for the minority language speaking child to function in the } \\
\text { majority language community as quickly as possible and equality of opportunity with } \\
\text { mainstream peers and maximization of minority pupil performance. Linguistically, the aim of } \\
\text { this model is monolingualism behind the rhetoric of equal rights and opportunities" (p. 26). }\end{array}$ \\
\hline Maintenance & $\begin{array}{l}\text { Stroud (2002) contends that it "aims at strengthening cultural identity and civil rights } \\
\text { affirmation, through the sheltered maintenance of the mother tongue. A distinction in } \\
\text { maintenance goals has been made between static maintenance, referring to the goal of keeping } \\
\text { children's language skills at the level they were at when entering school and preventing } \\
\text { language loss, and developmental maintenance, which aims to develop the students' skills in } \\
\text { the minority language to full proficiency" (p. 27). Baker (1996) justifies giving a maintenance } \\
\text { programme based on the fact that a minority language is easily lost, but a majority language is } \\
\text { easily gained. }\end{array}$ \\
\hline Enrichment & $\begin{array}{l}\text { Have two aims. Maintenance and development \& extension of the minority language. Seeking } \\
\text { the affirmation of cultural pluralism and an integrated national society based on autonomy of } \\
\text { cultural groups (see Fishman, 1976 and Hornberger, 1991). }\end{array}$ \\
\hline Restoration & $\begin{array}{l}\text { Aim to "revitalize a language and its community of speakers. Adults partially competent in the } \\
\text { language are also targets for this type of programme" (Stroud, 2002, p. 27). }\end{array}$ \\
\hline
\end{tabular}

Source: Stroud, 2002, pp. 26-27.

The transitional model is most frequently applied, at least in the Western world, although most proponents of bilingual education adhere to the maintenance view. Probably, because of the strong assimilative pressure of mainstream society, however, in some developing countries the situation is different.

Gaarder (1976) considered elitist bilingualism compared with folk bilingualism to distinguish bilingual education. Elitist bilingualism, which derives from choice, serves the interests of the dominant power group and upper-class membership. Therefore, having knowledge of two languages may have high cultural and economic value, allowing access to privileged groups or high-status positions and power. On the other hand, folk bilingualism, which derives from either necessity or compulsiveness, serves the bilingual person to survive. For example, immigrants who are seeking employment may need to learn the majority language, and bilingualism may be imposed by those politically dominant. Consequently, the distinction between the two bilingualism choices is necessary to highlight the motives of children during and upon entry to bilingual schooling.

\subsubsection{The Use of Two Languages}

Romaine (1998) conducted an experiment on code-switching and language mixing in the Panjabi-speaking community in Birmingham-UK. The aim was to study attitudes to language where a bilingual speaker switches between two languages in conversational interaction. The mode of the conversation goes by asking questions in Panjabi and receiving answers in English to bilingual individuals. Her observations were as follows: "First, at the linguistic level, there was code-switching as the experiment was intended. Secondly, from a psychological perspective, there is the question of awareness. Neither the interviewer (bilingual Panjabi/English speaker) nor the informant thought there was anything unusual about the exchange. The switch had gone unnoticed by both parties" (Romaine, 1998, p. 120). Similarly, Appel and Muysken (1987, p. 117) drew a passage from Valdes Fallis (1976) to reflect code-switching between two bilingual (Spanish/English) individuals. Exhibit 4 depicts the passage. 
Exhibit 4. Code switching

\author{
"OYE (listen), when I was a freshman I had a term paper to do...
}

And all of a sudden, I started acting real CURIOSA (strange), you know. I started going like this. Y LUEGO DECIA (and then I said), look at the smoke coming out of my fingers, like this. And then ME DIJO (he said to me), stop acting sill. Y LUEGO DECIA YO, MIRA (and then I said, look) can't you see. Y LUEGO ESTE (and then this), I started seeing like little stars all over the place. Y VOLTEABA YO ASINA Y LE DECIA (and I turned around and said to him) look at the... the... NO SE ERA COMO BRILLOSITO ASI (I don't know, it was like shiny like this) like stars".

Source: Appel and Muysken, 1987, p. 117.

\title{
1.6 Code-switching
}

Code-switching was coined by the sociolinguist Einar Haugen. It described "language alternation, or the mixing of two or more languages, or dialects. Albeit, the practice had been known since the early 20th century" (Harris, 2019, para 4). Gumperz (1982) uses the term 'code-switching' as "the juxtaposition within the same speech exchange of passages of speech belonging to two different grammatical systems or subsystems" (p. 59). In code-switching discourse, according to Romaine (1989), "the items in question form part of the same speech act. They are tied together prosodically (Wiklund, 2018) as well as by semantic and syntactic relations equivalent to those that join passage in a single speech act" (p. 111). This kind of linguistics behavior can routinely occur in both monolingual and bilingual communities.

Code-switching is different in many respects from diglossia. Diglossia, a social phenomenon, occurs where two languages or varieties co-exist and are specialized according to function. Romaine (1998) used Ferguson's (1972) argument that states that "the superposed variety referred to as "High" or simply ' $\mathrm{H}$ ', and the other variety (ies) as "Low" or ' $\mathrm{L}$ '. In one set of situations only $\mathrm{H}$ is appropriate, while in another, only L. For example, in all the defining speech communities it is typical to read aloud from a newspaper in H and discuss its contents in L" (p. 33). Ferguson (1972, cited in Leonardi, 2016) notes "nine separate areas in which H and L may differ: namely, function, prestige, literary, heritage, acquisition, standardization, stability, grammar, lexicon and phonology" (p. 34). Furthermore, and across the globe, the English language is only one of a number of languages which is at the disposal of the speakers. In communities where bilingualism and multilingualism abound, the selection of one language in preference to another is a matter of style. According to Graddol, Leith \& Swann (1996), "when a person opts for English or another language, speakers were tapping into a whole set of social meaning with which the language has become associated. But bilingual speakers need not keep their languages separate, so they use code-switching" (p. 314). Code-switching, then, is to switch back and forth between languages, thus capitalizing on the associations of each language, or "keep a foot in each camp".

Code-switching per se may be the unmarked (expected) choice in certain contexts. "As speaker's choice of language has to do with maintaining or negotiating a certain type of social identity. In fact, the use of a particular language also gives access to rights and obligations associated with that identity" (Graddol, Leith \& Swann, 1996, p. 314).

According to the functional model suggested within the context of sociolinguistic literature, Appel and Muysken (1987) identified six functions as follows: “(1) the referential function which involves lack of knowledge of one language or lack of facility in that language on a certain subject. Certain subjects may be more appropriately discussed in one language, and the introduction of such a subject can lead to a switch. In addition, a specific word from one the languages involved may be semantically more appropriate for a given concept. This type of switching is the one that bilingual speakers are more conscious of. Example here is broadcasting for immigrant populations; (2) the directive function which involves the hearer directly and it can take many forms. One is to exclude certain persons present from a portion of the conversation. The opposite is to include a person more by using her/his language. A person may have joined the participants in an interaction. All participant-related switching can be thought of as serving the choice or directive function of language use. Example here is the parent-to-parent conversation in a foreign language while children are present; (3) the expressive function whereby speakers emphasize a mixed identity using two languages in the same discourse. For example, fluent bilingual Puerto Ricans, Moroccans, Lebanese...; (4) A change in tone indication of the conversation, and hence a phatic function. It is called metaphorical switching. For example, the stand-up comedian who tells the whole joke in a standard variety but brings the punch line in a vernacular type of speech, e.g., an urban dialect; (5) the metalinguistic function of code-switching which comes into play when it is used to comment directly or indirectly on the languages involved. That is, when speakers switch between different codes to impress the other participants with a show of linguistic 
skills. Examples are performers, circus directors, and market salespersons; (6) Bilingual language usage involving switched puns, jokes, etc. can be said to serve the poetic function of language. Using complex internal rhymes across several languages" (Appel and Muysken, 1987, p. 118).

It is imperative to keep in mind that it is by no means certain that code-switching has the same functions across cultures or within each community. A sociolinguistic typology of code switching communities focusing not only on who switches but also on why people switch, is one of the research priorities for the immediate future. Finally, the typical features of a fluent switcher are possessed by those speakers who have learned both languages at an early age and they have reached such level of proficiency necessary to be able to use two or more languages in one single sentence. Speakers who switch most, are also those who are capable of switching in the middle of a sentence, a practice noted with the Lebanese.

\subsubsection{Types of Code-switching}

Poplack (1980; cited by Romaine, 1998, p. 122) identified three types:

(1). Tag-switching (or emblematic switching) is about inserting a tag in one language into the utterance which is otherwise entirely in the other language, e.g. you know, I mean, etc., to take some English examples.

(2). Inter-sentential switching involves a switch at a clause or sentence boundary, where each clause or sentence is in one language or another. It may also occur among speakers' turns. Example here is, "Y LUEGO DECIA (and then I said), look at the smoke coming out of my fingers". Or as seen in this expression too: "Sometimes I'll start a sentence in English y termino in Espanol" (Poplack, 1980, p. 581).

(3). Intra-sentential switching occurs when switching of different types within the clause or sentence boundary. It is arguably, the greatest syntactic risk, and may be avoided by all but the most fluent bilinguals. For Example, intimate switching or code mixing: "And all of a sudden, I started acting real CURIOSA (strange)" (Appel and Muysken, 1987, p.118). Also, "I could understand que [that] you don't know how to speak Spanish, verdad? [right]" (Poplack, 1980, p. 596). Furthermore, according to Waddell (2017), "Code-switching has become part and parcel of the spoken Lebanese Arabic, which has become strutted with French and English" (para 7). In fact, Tohme (2019) provides several examples of code-switching from the Lebanese everyday conversation. "3anjad amazing, chapeau bas!" meaning "really amazing, respect!" and "Maitre, el 7seb please" meaning "Waiter, check please".

Moreover, all three types of code-switching may be found within one and the same discourse. This kind of speech goes by the name of 'mix' or 'mikijimap" (mix-im-up). According to Romaine (1998), this "mixed speech style is common among people between the ages of 20 and 60 and involves both intra-sentential and inter-sentential codeswitching" (p. 123).

\subsubsection{Interference}

As Romaine (1998) asserts, "interference is one of the most commonly described and hotly debated phenomenon of bilingualism" (p. 51). There is a continuous debate about definition and identification among several concepts in bilingualism like borrowing, transfer, convergence, and code-switching. What makes this issue more complicated is the broadness associated when considering the contexts of individual as well as social aspects.

When the bilingual person uses more than one language in everyday interaction, then the product is 'Interference'. Considering the individual level, interference may be sporadic and idiosyncratic. However, it is cumulative on the social level, and leads to new norms that are different from those observed by monolinguals who use the languages elsewhere. Interference assumes the following:

1. In each case, one can identify the language. That is, any speech event belongs to a definite language.

2. Structures of the languages involved are relatively known, independently described and available for comparison.

\subsubsection{Borrowing}

Romaine (1998) quotes the definitions used by "Weinreich (1968) who differentiates between interference and borrowing as the first being a rearrangement of patterns from one language to another, and the second as the simple transfer or borrowing of an element from language to another; also, Mackey (1968) defines interference as contingent and individual, while borrowing is collective and systematic" (pp. 51-52).

According to Larousse dictionary (n.d.), "Borrowing is the process by which a language incorporates a significant element (generally a word) from another language" (para 3). That is, according to Graddol et al. (2020), "when 
language A uses and ends up absorbing a linguistic item or feature which was part of language $\mathrm{B}$, and which language A did not have, then borrowing occurs". Moreover, Graddol et al. (1996), contend that "borrowings only feel foreign if they have not had the time to become integrated into the host language. The English language is full of borrowings from Latin (mansion, cart, street), or Danish (place names ending in -by or -thwaite) (Crystal, 1988). But they have been part of the English language so long that no one would now point to them as being foreign" (p. $33)$.

Romaine (1998) and Caccamo (1998) stress Haugen's (1956) distinction between three concepts: “(1) Switching, the alternate use of two languages, (2) Interference, the overlapping of two systems to the same item, and (3) Integration, the use of words or phrases from one language that have become so much part of the other that it cannot be called either switching or overlapping except in a historical sense" (Romaine, 1998, p. 52; Caccamo, 1998, p. 43).

\subsection{Bilingualism in Lebanon}

Lebanon is one of the few countries in the world where foreign language education is integrated since the first or the second year of schooling. Shaaban (1996) contends that since 200 years, Lebanon continues to experience bilingualism, and in few cases, multilingualism in its educational system. In fact, since the early 1800s, western missionaries founded modern Lebanese schools including Turkey, the United States of America, France, England, Prussia, and Russia (Al Shamat, 2009; Baladi, 2018). These schools stressed education in their original languages, English, French, Turkish (or old Ottoman), German, Russian... as well as in the native language, Arabic. However, as time passed, the established missionaries in Lebanon created a conflict and a competition between the French Jesuits and the American Evangelical Protestants, in particular. This competition led to the establishment of numerous English-teaching and French-teaching schools all over the country (Womack, 2012, Shaaban, 2017).

This experience with western-type schools in Lebanon was a bilingual one, that is, with different foreign languages including French, English, Russian and Turkish pairing with Arabic as a media of instruction in the various schools. This experience of bilingualism has become entrenched in the Lebanese psyche and the Lebanese educational system. In fact, Abou's (1961) survey on bilingualism in Lebanon reported that the most common language used in education in the 1950s was the French language. Furthermore, since Lebanon won its independence, Arabic was declared as the only official language in the country. Consequently, Arabic was used as a medium of instruction for all subjects. However, an analytical reading of the above legislation indicates clearly that there was a pull in two directions. The first strengthened the feeling that the mother tongue 'Arabic' should be given prominence in the curriculum. The second, brought forward the long-established influence of the foreign language as a medium of instruction. Notwithstanding, pragmatism won over principles and the mother tongue 'Arabic' took second place to the influential French/English as the latter was perceived as a means of prestige and empowerment in the job market.

One can easily mention that the Lebanese educational system was highly influenced by the different historical stages. During the 18 years of civil war, thousands of Lebanese families and young people left the country for economic, security and ideological reasons. Their countries of destination varied between France, the USA, African countries, Canada, Australia, and the Arabian Gulf countries. This forced immigration was in itself a good incentive and a booster for these people to learn the languages of the hosting countries. Years later, according to Bacha \& Bahous (2011, p. 1321) and Chehimi (2002, p. 8), "Lebanese returnees constitute at present true bilinguals' communities who practice their bilingualism in their daily dealing. In fact, Chehimi (2002) asserts that "all returnees send their children to foreign language-oriented schools and do their shopping at special shopping centers modeled after their counterparts in the west, including having clerks who can communicate in a foreign language" (p. 8).

Shaaban (1997) propounds that "bilingualism has been and continues to be a cherished tradition in Lebanon in general, and in the Lebanese educational system in particular" (p. 257). Even though Lebanese say that they support the cause of the mother tongue 'Arabic', they do nothing to prove their support. The real fact remains that Arabic occupies a second place to the foreign language in the Lebanese school. Further, the Lebanese government allowed the adoption of foreign languages as the medium of instruction in public schools. This policy and practice could prove detrimental to the cause of Arabic that is losing ground and prestige in schools especially elementary schools. Zakaria (1992) asserts that policies like the aforementioned have great implications on the formation of national identity and the sense of belongingness.

\subsection{Closing Remarks for Section One}

It is quite admirable when a person is fluent in two or more languages. Every language a person acquires gives $\mathrm{him} / \mathrm{her}$ a great feeling of achievement by embracing new cultures. This fact will enable the person to understand others through flexibility. Understanding others is what one may call "open mindedness". 
Bilingualism has its advantages and disadvantages. One of its most admired advantages is the discovery of new means for knowledge acquisition and the opening of new social dimensions (Fornůsková, 2011). However, it is imperative for people to keep in mind that their mother tongue is essential to their personality and to their life. People should never lose their identity or their sense of belongingness. Knowing another language does not create another person but helps that same person adapt to a new culture whenever the need of this language arises.

In the last two decades, the developed countries have been sharing a common concern about the new emerging languages resulting from the vast amount of regulated immigration. Governments have been and still are concerned about the solutions for the integration of immigrants into their societies and cultures (Penninx, 2019). It has been a difficult task due to the presence of the controversies discussed, in this research project, related to the definition of bilingualism and the many varieties available.

There are two common trends that were identified, and these are:

1. Nations worrying for the conservation of immigrant's mother tongues through the process of societal integration (Canada, USA, England, Australia, ...) (see Brink et al., 2012, p. 219).

2. Nations worrying for the conservation and the recreation of old cultures and languages (Wales, Ireland, Scotland, African Countries, ...) (see Little, 2018; Cole \& Williams, 2004).

The researcher believes that bilingualism is a very controversial issue. Using two languages with the same proficiency can be very beneficial as a mean of survival in this dynamic world. It can be an achievement in a sense of opening up to new cultures, a fact that will enable the person to understand others. This fundamental reality is practiced best when chatting is carried out by communicating with the virtual community.

It is a fundamental requirement to have a well-established language base in order to enrich a person's knowledge using other languages as a new medium of inquiry. However, the new acquired language should not cancel the mother tongue for the sake of conserving one's identity. And whenever people seek solely the acquired new language, then most probably identity crisis, confusion or loss will result.

Lebanon is a good example where people are seeking new languages to replace one of the greatest languages in the world, namely, Arabic. Many Lebanese are apparently losing or have already lost their identity. They have no sense of belonging. In fact, "Arabic is the official language of Lebanon, but English and French are widely used. Most Lebanese speak French - a legacy of France's colonial rule - and the younger generation gravitates towards English" (Shawish, 2010, para 8-9). This phenomenon is the outcome of many immigrations to various parts of the world. Adding to that, the intended and/or accidental ignorance that surrounded them and made them unaware of the importance of their own heritage. "It is sad no-one in our generation is speaking Arabic properly anymore," says Lara Traad, a 16-year-old student at Notre Dame de Jamhour, one of Lebanon's many French curriculum schools..." (ibid, para 11). "I really regret that my parents did not concentrate more on developing my Arabic. It's too late now, but maybe for the younger students in the country something can be done" (ibid, para 12).

\subsection{Objectives of the Study}

The Lebanese bilingual experience with western-type schools whereby at least one of the languages namely, French, English, Russian and Turkish paired with Arabic became salient and unique. The bilingual choices were in fact the medium of instruction in the various schools (Thonhauser, 2000; Chehimi, 2002). Lebanese bilingualism has proved its viability with time and has become entrenched in the Lebanese psyche and the Lebanese educational system. "In fact, linguistic plurality has been an esteemed tradition throughout the country's history" (Hodeib, 2007, para 3).

Lebanon is known in the Middle East area as the land of people with multi-lingual capabilities. It was reviewed earlier that using two languages with the same proficiency can be very beneficial as a mean of survival in this dynamic world. It can also be an achievement in a sense of embracing new cultures, a fact that will enable the person to understand others. "Lebanon's familiarity with Western-style education, since the bourgeoning of missionary schools in the 19th century, set the foundations for a tradition of bilingualism that has proven its viability over the years and become entrenched in the Lebanese psyche and the Lebanese educational system, said Kassim Shaaban, a linguistics professor at the American University of Beirut" (Hodeib, 2007, para 6).

This research aims to:

(1) Assess how a sample of Lebanese students use their languages skills while carrying an on-line conversation through chatting.

(2) Explore the principles and processes guiding the practice of chatting, the rules and principles defining multi-linguistic use of languages, and the factors affecting the use of specific languages in society. 
(3) Investigate the variations governed by sociolinguistics branding the Lebanese chatting community.

(4) Assess the attitude of the students in their usage of languages while chatting on-line that is, chatting using their mother language (Arabic) in combination with specific foreign languages. A special attention is given to Internet literacy, chatting literacy, and multi-linguistic preferences.

\section{Research Methodology}

This study follows a mix of quantitative and qualitative approaches capitalizing on deductive and Inductive reasoning, respectively. The aim then is "to test a previous theory in a different situation or to compare categories at different time periods" (Elo \& Helvi, 2008, p. 107). Its philosophy is that of positivism (Hejase \& Hejase, 2013, p. 77). The research design is exploratory based on a questionnaire and an interview administered to individuals or companies face-to-face or via several media including telephone, mail, or email (Hejase \& Hejase, 2013, pp. 114-115). Nevertheless, a compendium of secondary data was obtained and collected from magazines, periodicals, Internet articles, and books. These data were used to build up a theoretical foundation that helps provide an adequate background information and guidelines for the research.

\subsection{Primary Data}

The existing body of knowledge related to linguistics in Lebanon is limited and the use of languages' mixing in chatting is a rare fact. This unique reality makes the need for primary data unavoidable. Therefore, primary data was generated from two research tools namely, interviews and surveys. Interviews were conducted using structured questions for the sake of obtaining uniform responses that make comparisons possible and the questionnaire was standardized to ensure that wording and order of questions is not changed from one respondent to another. Respondents were promised confidentiality to help them feel at ease in providing their true opinion and attitudes. Their willingness was an important factor for participation. The data was collected in the six months period extending from January 2019 to June 2019.

\subsection{Sample Selection}

This study depended on a conveniently selected sample of respondents selected from several Lebanese universities. A questionnaire was designed as a research tool in order to provide a common basis for comparison between the responses of the target sample of students. This method was used for simplicity and for time convenience since results could be collected from a larger sample as compared to an interview method. One hundred and twenty questionnaires were distributed. However, 14 questionnaires were returned half filled, 6 were filled hastily and 3 were with names. The aforementioned were removed and a final valid sample of 97 was selected. The response rate was $80.83 \%$ which is considered adequate. Students belonged to four different classrooms in three educational institutions conveniently selected. The researcher administered the questionnaires personally to avoid any misinterpretations from the respondents' side.

\subsection{Questionnaire Design}

The questionnaire was adopted from Chehimi (2002). It was divided into four sections reflecting computer literacy, chatting literacy, chatting language specifics, and demographics. Each section contained on the average a set of 12 questions (ranging from 9 to 15 questions in each category). The intention was to generate fast responses that could contribute to this exploratory research. Before administering the questionnaires, validity was checked by selecting two groups, the first consisting of four instructors and the second having twelve students who responded to the questions and corrections were made.

\subsection{Interviews Design}

Formal interviews were the primary method of data collection for qualitative research. At each interview, each respondent completed a brief demographic profile about education, age, gender, address, and number of chat hours per day. The interviews were directive, structured, brief and including open-ended questions. It was simplistic in nature aiming at providing ease and friendliness to attract sincere responses related to linguistics in chatting, educational values, language preferences, and attitude toward chatting language requirements. Respondents were calm and under no stressful conditions physically or psychologically.

The interviews were conducted in a period of one month (April 2019 - May 2019). Interviewees were encouraged to respond objectively. The interview time was ten minutes each. The number of interviewees consisted of 39 persons. However, their selection was convenient and without a prior knowledge of whether they chat or not. 


\subsection{Data Analysis}

All data were coded and input into the computer using the Statistical Product and Service Solutions - SPSS version 23 software, an IBM product since 2009 (Hejase and Hejase, 2013). To analyze and interpret this research output, descriptive statistics was used. This kind of analysis is used to rearrange, order, or manipulate the raw data to transform it into a form that will make it easy to understand and interpret. The descriptive analysis includes the use of frequencies, percentages, means and variances. Relevant observations and comments are easier to make.

Since the sample of respondents was chosen on convenience, and to avoid the error of providing inaccurate or unreliable information, the output is not projected to the whole target population.

\section{Results and Findings}

English has become a global language and it is the most used language on the Internet. In fact, "people often talk about English as a global language or lingua franca. With more than 350 million people around the world speaking English as a first language and more than 430 million speaking it as a second language" (Wil, 2017, para 1). Also, Zazulak (2015) contends that "more than half of all content on the internet is in English. This is simply because it is considered a 'universal language', often chosen by people of different nationalities as a common way to communicate" (para 3). In this study the researcher explored the language(s) mostly used by the Lebanese students while chatting. A questionnaire was designed and administered by the researcher in person. The target was a conveniently selected sample of students in colleges and universities in greater Beirut area.

Lebanon is a country where most people are bilingual or even multilingual. In fact, Baladi (2018) contends that "Lebanon is today known as a true 'trilingual' country with all three languages [Arabic, English and French] spoken and celebrated in different ways" (p. 10). What drew the researcher's attention to this issue is the variety of languages being used among students while chatting. She was motivated after observing a strange mixture of languages. This research intends to provide an exploratory observation of these varieties and styles, in addition to the attitude of the students toward their native language (Arabic).

\subsection{Demographics}

The sample of respondents consisted of ninety seven (97) persons whose average age was 24 years (range 17 to 27 years), with $68.04 \%$ being males, and the majority of $53.61 \%$ living in Beirut and $18.56 \%$ living in Mount Lebanon. $83.51 \%$ were college students and $16.49 \%$ had postgraduate education. Table 1 shows the demographic details.

Table 2 shows details of the language characteristics of the respondents. 52.58\% had English as their high school education, $17.53 \%$ used French, $11.34 \%$ used Arabic and English, 6.19\% used Arabic only, 5.15\% used Arabic and French, and $7.21 \%$ were trilingual. However, $58.76 \%$ use Arabic as their home spoken language (mother tongue), 14.44\% speak Arabic and English, 7.22\% use Arabic and French, 2.06\% use Armenian, and 5.15\% use a trilingual mix.

Table 1. Sample Demographics

\begin{tabular}{|c|c|c|c|c|c|}
\hline $\begin{array}{c}\text { Age } \\
\text { Less than years } 18 \text { years } 19<\text { Age } \\
<22 \text { years } \\
23<\text { Age }<26 \text { years } \\
\text { Above } 26 \text { years }\end{array}$ & $\begin{array}{c}\text { Frequency } \\
8 \\
62 \\
24 \\
3 \\
\end{array}$ & $\begin{array}{c}\text { Percent } \\
8.24 \\
63.92 \\
24.74 \\
3.10 \\
\end{array}$ & $\begin{array}{l}\text { Gender } \\
\text { Male } \\
\text { Female }\end{array}$ & $\begin{array}{c}\text { Freq. } \\
66 \\
31\end{array}$ & $\begin{array}{c}\text { Percent } \\
68.04 \\
31.96\end{array}$ \\
\hline Total & 97 & $100.00 \%$ & & 97 & $100.00 \%$ \\
\hline $\begin{array}{c}\text { Education } \\
\text { College } \\
\text { Postgraduate }\end{array}$ & $\begin{array}{l}81 \\
16\end{array}$ & $\begin{array}{l}83.51 \\
16.49\end{array}$ & $\begin{array}{c}\text { Type of Schooling } \\
\text { Attended } \\
\text { Public } \\
\text { Private }\end{array}$ & $\begin{array}{l}19 \\
78 \\
\end{array}$ & $\begin{array}{l}19.59 \\
80.41\end{array}$ \\
\hline Total & 97 & $100.00 \%$ & & 97 & $100.00 \%$ \\
\hline $\begin{array}{c}\text { Address } \\
\text { Beirut } \\
\text { Mount Lebanon } \\
\text { Southern Lebanon } \\
\text { Eastern Lebanon (Bekaa) } \\
\text { Northern Lebanon } \\
\end{array}$ & $\begin{array}{c}52 \\
18 \\
15 \\
5 \\
7 \\
\end{array}$ & $\begin{array}{c}53.61 \\
18.56 \\
15.46 \\
5.15 \\
7.22 \\
\end{array}$ & & & \\
\hline Total & 97 & $100.00 \%$ & & & \\
\hline
\end{tabular}


Table 2. Language Characteristics

\begin{tabular}{c|c|c|c|c|c}
\hline $\begin{array}{c}\text { Language of high school } \\
\text { education }\end{array}$ & Freq. & Percent & Language spoken at home & Freq. & Percent \\
Arabic & 6 & 6.19 & Arabic & & \\
English & 51 & 52.58 & English & 57 & 58.76 \\
French & 17 & 17.53 & French & 5 & 5.15 \\
Arabic/English & 11 & 11.34 & Arabic/English & 7 & 7.22 \\
Arabic/French & 5 & 5.15 & Arabic/French & 14 & 14.44 \\
Trilingual & 7 & 7.21 & Armenian & 7 & 7.22 \\
[Armenian/English/French] & & & Trilingual & 2 & 2.06 \\
\hline Total & 97 & $100.00 \%$ & & 5 & 5.15 \\
\hline
\end{tabular}

Table 3. Parents' Education

\begin{tabular}{c|c|c|c|c|c}
\hline Father's Education & Freq. & Percent & Mother's Education & Freq. & Percent \\
None & 3 & 3.09 & None & 4 & 4.12 \\
High School & 33 & 34.02 & High School & 51 & 52.58 \\
College & 21 & 21.65 & College & 21 & 21.65 \\
Postgraduate & 36 & 37.12 & Postgraduate & 21 & 21.65 \\
Vocational & 4 & 4.12 & Vocational & 0 & 0.00 \\
\hline Total & 97 & $100.00 \%$ & Total & 97 & $100.00 \%$ \\
\hline
\end{tabular}

Tables 1 and 3 show that $80.41 \%$ of the respondents attended a private school, their father's education is $34.02 \%$ high school, $21.65 \%$ college, and $37.12 \%$ postgraduate. Their mother's education is $52.58 \%$ high school, $21.65 \%$ college, and $21.65 \%$ postgraduate.

\subsection{Computer Literacy}

Respondents in their grand majority (97\%) owned their personal computers with 68.04\% (66 out of 97) having ADSL (Asymmetric digital subscriber line) service as the mean of connection to the Internet, 11.34\% (11 respondents) using cable, while $20.62 \%$ (20 respondents) having both connections. Also, $84.54 \%$ use their computers six hours at most per day, whereby $62.9 \%$ of the students connected to the Internet between eight and eleven in the evening. $17.53 \%$ between twelve noon and eight in the evening while $19.57 \%$ used their computer between 12 midnight and three in the morning. 84\% use their Internet for the purpose of surfing the net for curiosity, $64 \%$ for chatting, and $54.64 \%$ for assignments. The aforementioned add to more than $100 \%$ because of multiple answers.

\subsection{Chatting Literacy}

$87.63 \%$ of the participants chat (i.e., 85 out of 97 students). The chat tool mostly used Instant Messaging (IM) Social Networks. MSN Facebook (67\%) and 32\% use a mixture of ICQ, MSN, AOL Instant Messenger (AIM) and Yahoo Messenger. $71.2 \%$ of the respondents chat for less than two hours per day, $26.8 \%$ chat between two and four hours, and $2 \%$ chat for more than four hours per day.

Table 4 shows that $51.76 \%$ of the respondents chat in English, 14.12\% chat in English and Arabic, and 28.25\% use a combination of languages. $58.76 \%$ of the participants are aware of Internet behavioral policies (Netiquette), all chatters have emails, and $95.3 \%$ of them (i.e., 81 out of 85 ) have Hotmail (relaunched as Outlook) and Gmail addresses. $83.53 \%$ (71/85) belong to chat groups, where only $22.35 \%$ (19/85) have their own chat rooms. 
Table 4. Chatting language used by respondents

\begin{tabular}{c|c|c}
\hline Language Used (Out of 85 Chatters) & Frequency & Percentage, \% \\
\hline English [E] & 44 & 51.76 \\
Arabic [A] & 6 & 7.06 \\
French [F] & 8 & 9.40 \\
Armenian & 3 & 3.53 \\
English / French & 4 & 4.71 \\
English / Arabic & 12 & 14.12 \\
French / Arabic & 4 & 4.71 \\
All Three (E / F / A ) & 4 & 4.71 \\
\hline Total & 85 & $100.00 \%$ \\
\hline
\end{tabular}

Table 5 gives details on chat topics. Results show that $36.47 \%$ chat to resolve personal problems looking for cyber solutions, and another $83.53 \%$ chat using a mixture of topics which also includes personal problems issues, sex, politics, music, and jokes.

Table 5. Chatting topics used by respondents

\begin{tabular}{c|c|c}
\hline Topics of Interest (Out of 85 Chatters) & Frequency* & Percentage, \% \\
\hline Politics & 51 & 60.00 \\
Sex & 11 & 12.94 \\
Jokes & 26 & 30.59 \\
Personal Problems & 31 & 36.47 \\
Music & 17 & 20.00 \\
Mix (including personal problems) & 71 & 83.53 \\
\hline * Multiple responses $>85$ & & \\
\hline
\end{tabular}

\subsection{Chatting Language Specifics}

$83.53 \%(71 / 85)$ of the students use English as written and spoken. $74.12 \%(63 / 85)$ of the students often $(36.47 \%$ $31 / 85)$ and very often $(37.65 \%$ - 32/85) introduce symbols and smileys in their writings, while $25.88 \%(22 / 85)$ sometimes do that. Furthermore, 85.88\% (73/85) of the respondents use English letters with Arabic sounds (for example: La lmwdou3 mish m7rez n7ki fi w ma asde etms5r 3 7ada which means: The subject is not worth to talk about it and I do not mean to mock anyone. Here, the text sounds Arabic for any Arab reader even if the student does not know a foreign language, but the reader only needs to be familiar with the English phonics-letters and sounds). Also, 81.18\% (69/85) mix Arabic and English conversational statements while chatting (for example, Please forgive me and try to assess my situation هههيه هيدا لطلع معي انشاله ما يكون في غلط ; Hehehehe...This is what I got, God Willing there are no mistakes). And 41.18\% (35/85) of the sample mix three languages namely, English, Arabic, and French or Armenian $(2.35 \%)$ (For example, Ttalla3it fiyeh bel eleb...Ma eblouneh bel job... ils m'ont rejeté... So is it bad to ask ur interviewer name?

Meaning: She looked at me with a wrong face (using Lebanese jargon ... giving a wrong face!) They did not accept me for the job... [Then using French]... They rejected me... then English).

When respondents were asked if they have certain preferences in their chat partners, results show that $51.76 \%$ of the respondents look for chat partners who are bilingual in Arabic and English, 3.54\% look for bilinguals in Arabic and French, 7.06\% in English and French, and 21.17\% look for trilingual partners in English, Arabic, and French. Table 6 shows the distribution of respondents' languages preferences. 
Table 6. Respondents' Chatting partners preferences

\begin{tabular}{c|c|c|c|c}
\hline $\begin{array}{c}\text { Preferred Partner's Language (Out of } \\
\text { 85 Chatters) }\end{array}$ & Frequency & Any Partner, \% & Frequency & $\begin{array}{c}\text { Lebanese } \\
\text { Partner, \% }\end{array}$ \\
\hline Arabic & 3 & 3.54 & 4 & 4.71 \\
English & 7 & 8.23 & 13 & 15.29 \\
French & 2 & 2.35 & 2 & 2.35 \\
Arabic / English & 44 & 51.76 & 46 & 54.11 \\
Arabic / French & 3 & 3.54 & 4 & 4.71 \\
English / French & 6 & 7.06 & 4 & 4.71 \\
Trilingual & 18 & 21.17 & 11 & 12.94 \\
Armenian & 2 & 2.35 & 1 & 1.18 \\
\hline Total & 85 & 100.00 & 85 & 100.00 \\
\hline
\end{tabular}

However, when the chatter looks for a Lebanese partner, in specific, his/her behavior changes to seeking $15.29 \%$ English speaker, 54.11\% who are bilingual in English and Arabic, 4.71\% look for bilinguals in Arabic and French, 4.71\% in English and French, and 12.94\% look for trilingual partners in English, Arabic, and French. Table 6 shows these results as well.

When respondents were confronted to choose a specific language to chat with, the grand majority $92.94 \%$ (79/85) chose English and the rest chose Arabic. Moreover, respondents were motivated further to express if their choice of chat language is for prestige reflecting social class, only $48.24 \%$ (41/85) agreed. The aforementioned results agree to a great extent with Chehimi's (2021, p. 24) findings in her research about 'Lebanese Students' Attitudes toward English" where $73.1 \%$ and $61.54 \%$ of high school students believe that all Lebanese should learn English and that English raises their social status, respectively. Next, all participating students were asked if they consider Arabic as a prestigious language, only $24.71 \%$ (21/85) agreed.

To stress the issue of Arabic language further, the respondents were asked if their keyboard is enabled with Arabic letters, will they chat in Arabic using Arabic characters, 24.71\% (21/85) confirmed they will. Out of 85 chatters only $16(18.82 \%)$ students admitted that they feel comfortable with the Arabic language as written and spoken. Worth to mention that Chehimi (2021, p. 24) found that $15.4 \%$ of high school students asked that "Teachers should be allowed to use Arabic in English classes" possibly reflecting that such a group of students are much more comfortable with their mother tongue while learning the second language.

Following the above behavior in using languages while chatting, respondents were asked about the language they think in when writing their messages, Table 7 (below) reflects that 52.94\% think in Arabic, $35.30 \%$ think in English, an equal number or $2.35 \%$ in French and Armenian, respectively and the remaining think bilingually.

Table 7. Language the respondents think with

\begin{tabular}{|c|c|c|}
\hline Thinking Language (Out of 85 Chatters) & Frequency & Percentage, $\%$ \\
\hline Arabic & 45 & 52.94 \\
\hline English & 30 & 35.30 \\
\hline French & 2 & 2.35 \\
\hline Arabic / English & 4 & 4.71 \\
\hline Arabic / French & 2 & 2.35 \\
\hline English / French & 0 & 0.00 \\
\hline Armenian & 2 & 2.35 \\
\hline Total & 85 & 100.00 \\
\hline
\end{tabular}

Finally, this section was finalized by asking the respondents to state the reason they chat. $42.35 \%$ (36/85) chat for fun, $24.71 \%(21 / 85)$ chat to meet new people, $32.94 \%$ (28/85) chat for multiple reasons including the first two reasons and in addition to these they consider chatting as a stress reliever, to waste time, and to resolve personal problems. 


\subsection{Findings_}

Nowadays, where social life is governed by different perspectives of social relations and people do not have the time to meet and interact, many resort to the cyber world where they can meet other people and chat with them. These meetings release people from the accumulation of time pressure and social misjudgments, as many students claimed it is much easier to sit at home and surf the net instead of going out and having to worry about the time and the expenses. Most students have their own computers, so they do not need to leave home for chatting. Most come online late at night because it is cheaper, and they have finished their schoolwork. The aforementioned is in line with Smith \& Anderson (2018) who reported that, "younger Americans stand out for embracing a variety of platforms and using them frequently. Some $78 \%$ of 18 - to 24 -year-olds use Snapchat, and a sizeable majority of these users (71\%) visit the platform multiple times per day. Similarly, $71 \%$ of Americans in this age group now use Instagram and close to half (45\%) are Twitter users" (para 2).

Chatting is mostly done for fun and as stress reliever. Being in the cyber world is like "being in a place where you are accepted no matter who you are and where you come from" (Chehimi, 2020, p. 46). Furthermore, Lyness (2018, para 4) encourages the young to put feelings into words because it helps them to use self-control when they feel mad or upset. Students in this sample are at an age where they need support, and many find the chatting tool as a support system because they can express themselves as they wish. In fact, Frisbie (2016) reports two chatting activities among fifteen activities to relief stress online namely 'Internet debates' and 'Oversharing' whereby chatters unstress themselves by sharing with others topics of interest.

Living in a country like Lebanon, puts students in situations where they have to use different languages in their daily lives (Thonhauser, 2000; Gustafsson, 2012; Esseili, 2017). These language situations are reflected clearly in the use of chat, in the selection of partners, and in their styles of communication. Most Lebanese students use a mix of languages but mostly they use an inter-mix of Arabic written with code numbers and English letters i.e., mar7aba bil 3arabi $\boldsymbol{w}$ bil franji (this means, hello in Arabic and in a foreign language); 7zar shu? (Guess what?); mna3ti monika irshein 7elween (we can give Monica some good money). From these examples one can see that students are familiar with typing in English, but they express themselves better in Arabic (please refer to Table 8 for the meaning of the numbers to stress specific sounds pertaining to the Arabic language.... Also, see Table A in Appendix for exhibits from several chatting sessions).

Table 8. Numbers representing Arabic language sounds

\begin{tabular}{c|l|c}
\hline Number & Arabic Sound & $\begin{array}{l}\text { Equivalent Arabic } \\
\text { Letter }\end{array}$ \\
\hline 2 & $\begin{array}{l}\text { The Hamza/glottal stop pronunciation is favored in CA, the '2' is subbed } \\
\text { in for it }\end{array}$ \\
\hline 3 & The letter 'Ain' is favored in CA, the '3' is subbed in for it \\
\hline 5 & The letter 'Kha' is favored in CA, the '5' is subbed in for it & $\varepsilon$ \\
\hline 6 & The letter 'Tah' is favored in CA, the '6' is subbed in for it & $\dot{C}$ \\
\hline 7 & The letter 'Hah' is favored in CA, the '7' is subbed in for it & $\tau$ \\
\hline 8 & The letter 'Qaf' is favored in CA, the '8' is subbed in for it & ق \\
\hline
\end{tabular}

Source: Talk in Arabic, 2021.

Note: Colloquial Arabic: CA

In 2010, a Lebanese Language Institute (2010) blog asserts that, “Today, most people that use the Latin letters to write the Lebanese language on the web insert letters (numbers representing Arabic letters) in the words they use to substitute for sounds that exist in the Lebanese language and that are lacking in the Latin alphabet" (para 1). A fact that created negative vibes among people since many adolescents and university students were chatting with non-Lebanese as well and used the previously mentioned inter-mix. However, what characterizes the chat language used among Lebanese students as unique (bilingual or trilingual), is the ease of mixing of languages [ranging between 2 or 3 languages and sometimes more]. This asserts the multilingual society where Lebanese live in and where they were reared. For example, Tohme (2019) used the following chat as an example, "3anjad amazing, chapeau bas!" which mixes three languages, "3anjad = عن جد (Arabic written with Latin letters and using the number 3 for the letter Ain [ع] in Arabic) = meaning truly in English" followed by "amazing" in English, and the in French "chapeau bas" [meaning taking a hat off in respect]. Furthermore, according to Hodeib (2007), "Lebanese 
Arabic contains many instances in which these three languages - English, Arabic and French - are mashed together in the same sentence. For example, Lebanese youth make plans for the night by asking, "Shou, rayhin clubbing ce soir? (So, what, are we going clubbing tonight?)" (Para 2). It is worth mentioning that another salient characteristic observed is the flexibility in shifting between languages. A student can be addressing someone in the mother tongue 'Arabic', though if the respondent answers in French or English (or another language), that student tries to make use of his/her other language even if he/she has fair literacy. This flexibility raises the status of a Lebanese when compared to other Arabic - speakers (see above example). Other examples from this research include: (I don't want to work tete a tete with him! [Combination English and French]. Meaning 'I do not want to work head-to-head with him'; Ttalla3it fiyeh bel leb [Arabic using numbers and English letters]... Ma eblouneh bel job [Arabic using English letters and English]... ils m'ont rejeté! [French]. Meaning 'She looked at me in a wrong way... I was not accepted for the job.... They rejected me').

When these students were asked about Arabic and if they thought of it as a prestigious language, most claimed it is not a prestigious language. From this, an inference can be made that Lebanese people always seek to learn and speak other languages because they do not hold any prejudice for their own language or consider it prestigious in such a way they do not seek new languages (Sayigh, 1965). Moreover, since Arabic is not considered a feature of upper class most Lebanese try to resort to other languages to close that gap. But this fact does not help completely this task since the majority still thinks in Arabic while they speak or write in a foreign language. Moreover, another observation with Lebanese chatters is that when one of them accesses a chat room administrated by a Lebanese, he/she does not use written colloquial Arabic, rather he/she uses local Arabic written with English letters and numbers representing Arabic sounds. Contrary to the situation when one accesses a chat room administrated by Arab chatters (Saudi, Syrian, UAE, Kuwaiti or other non-Lebanese), only written Arabic is used (and many instances using the corresponding country dialects).

\subsection{Interviews Sample}

Results will be reported next to reflect what the interviewed students expressed.

\subsubsection{Demographics}

Fifty people were invited for the interview. However, the final sample size of interviewees consisted of thirty-nine persons (with a response rate of 78\%) whose average age was 24 years (range 18 to 45 years), with $74.35 \%$ being males, and the majority of 51.28\% living in Beirut and 23.08\% living in Mount Lebanon. $66.67 \%$ were college students and the rest or $33.33 \%$ had a master degree. Table 9 shows the demographic details.

Table 9. Interviewee sample demographics

\begin{tabular}{|c|c|c|c|c|c|}
\hline $\begin{array}{c}\text { Age } \\
\text { Less than years } 18 \text { years } 19< \\
\text { Age }<22 \text { years } \\
23<\text { Age }<26 \text { years } \\
\text { Above } 26 \text { years }\end{array}$ & $\begin{array}{c}\text { Frequency } \\
0 \\
26 \\
11 \\
2\end{array}$ & $\begin{array}{c}\text { Percent } \\
0.00 \\
66.67 \\
28.21 \\
5.12 \\
\end{array}$ & $\begin{array}{c}\text { Gender } \\
\text { Male } \\
\text { Female }\end{array}$ & $\begin{array}{c}\text { Freq. } \\
29 \\
10\end{array}$ & $\begin{array}{c}\text { Percent } \\
74.35 \\
25.65\end{array}$ \\
\hline Total & 39 & $100.00 \%$ & & 39 & $100.00 \%$ \\
\hline $\begin{array}{c}\text { Education } \\
\text { College } \\
\text { Postgraduate }\end{array}$ & $\begin{array}{l}26 \\
13\end{array}$ & $\begin{array}{l}66.67 \\
33.33\end{array}$ & $\begin{array}{c}\text { Type of Schooling } \\
\text { Attended } \\
\text { Public } \\
\text { Private }\end{array}$ & $\begin{array}{c}9 \\
30\end{array}$ & $\begin{array}{l}23.08 \\
76.92\end{array}$ \\
\hline Total & 39 & $100.00 \%$ & & 39 & $100.00 \%$ \\
\hline $\begin{array}{c}\text { Address } \\
\text { Beirut } \\
\text { Mount Lebanon } \\
\text { Southern Lebanon } \\
\text { Eastern Lebanon (Bekaa) } \\
\text { Northern Lebanon }\end{array}$ & $\begin{array}{c}20 \\
9 \\
5 \\
3 \\
2\end{array}$ & $\begin{array}{l}51.28 \\
23.08 \\
12.82 \\
7.69 \\
5.13\end{array}$ & & & \\
\hline Total & 39 & $100.00 \%$ & & & \\
\hline
\end{tabular}




\subsubsection{Chatting literacy}

$92.31 \%$ of the interviewed students chat (36 out of 39 students). However, $15.38 \%$ (6/39) of the interviewees rarely chat, $58.97 \%$ (23/39) chat sometimes, and another $25.65 \%$ (10/39) chat on a regular basis. The chat tool mostly used is MSN Facebook (65.8\%) and 34.2\% use a mixture of ICQ, MSN, AOL Instant Messenger (AIM) and Yahoo Messenger. The grand majority or $89.74 \%$ (35/39) chat for less than three hours per day, $10.26 \%$ (10/39) chat between four and six hours.

\subsubsection{Chatting language specifics}

Interview results show that 87.18\% (34/39) chat in English, 7.69\% (3/39) chat in English and Arabic, and 5.13\% $(2 / 39)$ the rest use a mixture of languages. All chat users have at least two emails, and the majority of $76.92 \%$ (30 of 39) have Hotmail (or its update Outlook) addresses.

Moreover, respondents were motivated further to express if their choice of chat language is for prestige reflecting social class, $41.0 \%$ (16/39) agreed. Next, all participating students were asked if they consider Arabic as a prestigious language, $46.4 \%$ (13 of 28) agreed. To stress the issue of Arabic language further, the respondents were asked why they attribute the word "prestigious" to Arabic they said that using the Arabic slang while chatting is very attractive, branded, and unique.

Finally, this section was finalized by asking the respondents to state the reason they chat. 53.85\% (21/39) chat for fun, $7.69 \%$ (3/39) chat to communicate and meet new people, $7.69 \%$ (3/39) chat to kill time, and 30.76\% (12/39) chat for learning purposes. However, when asking those 12 persons who responded that they chat for learning purposes, what specifically they aim to learn, 8 said that they prefer languages and the other 4 prefer literature and history.

Moreover, when they were asked if chatting became a tool used only for learning, will they continue chatting? 66.67\% (26/39) responded positively to this question. And when they were asked what other topics call their attention while chatting a long list of a variety of topics was provided. Table 10 shows these topics.

Table 10. Topics the respondents are interested to learn

\begin{tabular}{c|c|c}
\hline Topic & Frequency & Percentage, \% \\
\hline History & 3 & 7.69 \\
Language & 8 & 20.51 \\
Solving Problems & 3 & 7.69 \\
Health & 3 & 7.69 \\
Culture \& Society & 4 & 10.26 \\
Academic & 10 & 25.64 \\
Technology \& Computers & 6 & 15.39 \\
Music & 2 & 5.13 \\
\hline Total & 39 & 100.00 \\
\hline
\end{tabular}

\subsubsection{Chatting language specifics and Lebanese Chatters}

A very interesting observation is the match resulting between the surveyed group and the interviewed group. When the interviewees were asked what makes the Lebanese chatters so special, 51.28\% (20/39) agreed that the Lebanese chat language used is a mixture of languages (at least two different languages). This phenomenon has been asserted by many researchers (Thonhauser, 2000; Hodeib, 2007; Gustafsson, 2012; Esseili, 2017, and Tohme, 2019). However, $41.03 \%$ (16/39) commented that the Lebanese chatter has no special merit since nowadays everybody mixes languages anywhere, and $7.69 \%$ had no opinion about the question.

Another highly matching opinion is related to the flexibility in shifting from one language to another. All interviewees confirmed the fact that a Lebanese student can be addressing some one in Arabic, English, French, or even Spanish and German. Both samples agreed that such flexibility is what makes a Lebanese so unique among the Arabic - speakers, besides being humorous, intelligent, and open minded. Theses opinions fit well with Waddell's (2017) and Lebanese American University (LAU) professor Rula Diab's (quoted in Gustafsson, 2012) observations on code-switching in Lebanon and integration of one language's borrowings into another as asserted by Romaine (1998, p. 52), Caccamo (1998, p. 43), Graddof, Leith \& Swann (1996, p. 32) and Gustafsson, (2012, para 1-3). 


\section{Conclusion and Recommendations}

\subsection{Conclusion}

The widespread use of ICT applications supporting blended education for instructional purposes, as an enabler for alternatives to the traditional classroom, has encouraged the stakeholders (instructors and students alike) to approach teaching and learning in dynamic ways that incorporate collaborative learning and the social construction of knowledge (Harasim, 2012; Bates, 2015). Discussion and dialog among "chatters" in general, or between instructor and students and among students themselves, in specific, is a key feature of computer chatting. Computer chatting is used synchronously, allowing real-time, interactive chats or open sessions among as many participants as are online simultaneously.

This study reports an exploratory evaluation of using chatting as a communication tool to support purposeful communication and learning within the context of the virtual community. The idea was to take advantage of cyber-communication conventions (smileys, acronyms, language mixing, etc.) that real-time, interactive electronic chat-users developed in instructional settings. The study also determined that the chat users recognized a need to use their communication conventions to communicate clearly and minimize misunderstandings in their online transactions with others. Communication conventions included the use of keywords, symbols and names of individuals, shorthand techniques; acronyms and symbols, and asking questions and seeking clarification. The major outcome here is manifested using a descriptive style that, based on the findings, suggest that most chat users conduct chatting as entertainment, a fact that may justify the frustrations encountered during the quest of looking for value-added information that is capable to enrich their knowledge.

\subsection{Recommendations}

\section{* Policy makers', educational institutions' and instructors' roles must have clarity in purpose}

The use of language is very crucial for the development of language skills needed for future endeavors. It is the responsibility of educators, then, to implement the proper use of language, whether the language is the native language 'Arabic' or any foreign language (English, French, German, Spanish, etc) which is being taught at schools. Although having a multilingual society seems like a positive fact, this reality should not be taken for granted and languages must be directed properly. Students cannot be left without guidance to the use of any language. According to Hodeib (2007), "The Lebanese government's policies concerning language and various reports on the subject suggest a shift from Arabic/French bilingualism to Arabic/French/English 'trilingualism'. In fact, the Lebanese Constitution says that "at the end of their intermediate education, students can take official examinations in mathematics and sciences in Arabic or in a foreign language (French or English)" (Hodeib, 2007). In addition, Gaith and Shaaban (1996) quote in their research about language in education in Lebanon "two major objectives which were established and formulated in the Plan for Educational Reform (1994) and The New Framework for Education in Lebanon (1995) as follows: To form a citizen ... Who is committed to the Arabic language as all official national language and able to use it efficiently and effectively in all domains ... [and] who is proficient in at least one foreign language for the activation of openness to international cultures to enrich and be enriched by them" (p.103). Furthermore, LAU professor Rula Diab contends, "our education system gives priority to English and French. We start studying these languages since kindergarten. In many schools, English or French is the language of instruction, not Arabic. Arabic is used in social sciences including Arabic language and literature, history, and geography only. So kids were exposed to English or French, every day. To many of them, Arabic becomes secondary" (Gustafsson, 2012, para 3). To confirm the above, Byloun (2015) quotes the Ministry of Education and Higher Education (MEHE) in Lebanon, which aligns the use of the mother tongue and a foreign language in the curricula as follows: the languages of instructions in Lebanese public and private schools as follows:

(a) Subjects taught in Arabic are: Arabic, geography, history, and civics; and (b) Other subjects are taught in foreign language (English or French): physics, chemistry, biology, science, foreign language" (p. 14).

\section{* Guiding students to the proper use of chat language}

The researcher, an English instructor herself, has noticed that students are inconsistent to what language to use and when. Such inconsistency must call the attention from language teachers/instructors in their roles in providing guidance and direction whether it is the native language 'Arabic' or any other foreign language. What makes things more stressful for instructors is the students' use of the Internet and chatting language as practiced in their formal class writings. Indeed, Professor Hussin J. Hejase (Professor and senior researcher, personal communication, April $20,2020)$ confirms this negative impact as observed in many universities across Lebanon. Consequently, and as the researcher has observed as well in her classes, students used chat language in writing their English essays, that is by 
using symbolic and abbreviated terms embedded in their usual text, and this is the result of the neglect of language teachers/instructors who are not directing students well (observation asserted by Ms. Sarah Eid, Coordinator of English language teaching at Al Maaref University, personal communication, May 8, 2020). To prevent students from using chatting is impossible. However, teachers/instructors can use the chat tool to reinforce learning language (Robertson, 2014). They can create chat rooms to enable their classes where only the target language can be used, and in the proper form with definite instructions. Using the chat rooms to support blended language education in the classroom, it is possible to record the whole conversation and be used as reference for further lessons by both the instructors/teachers and the students. However, caution must be practiced because such facility cannot be possible under no rules academic conditions. Furthermore, Smutny and Schreiberova (2020, pp. 8-9) in their recent research on chatbots _ a chatbot is software tool that interacts with users on a certain topic (p. 8) _ report their efficiency in teaching is $57.2 \%$ and assert that Chatbot Edwin.ai is one of the top ten chatbots to support academic teaching of online English-language learning and offers tutor power by artificial intelligence.

\section{* Encouraging collaborative learning via Internet mediated educational tools}

As for Graziadei et al. (1997) quoting Johnstone (1992) and Twigg (1992) who affirmed that "technology does not guarantee productivity; but coupled with changes in pedagogy, economies of scale, and a paradigm shift to individualized, self-paced mastery learning, technology can make greater learning productivity possible" (p. 4). Worth mentioning that Bates (2015) asserted that, "there is enough evidence that collaborative learning can be done just as well online, which is important, given the need for more flexible models of delivery to meet the needs of a more diverse student body in a digital age" (Chapter 4).

The advantages of chat exercises match very much those observed by Al-Haq \& Al-Sobh, (2010) who quoted Frizler (1995) and other researchers in their research on the Internet mediated educational tool in ESOL writing instruction namely, "collaboration among participating students, motivation and enjoyment of the learning process, cross-cultural communication, awareness of global issues and concerns, creative outlets and opportunities for publication (in this case the continuous communication with selected respondents), and development of computer technology and networking skills" (p. 193).

\section{* Improving students' ICT literacy}

Furthermore, Jukes, McCain and Crockett (2010) assert that today's learners prefer to receive information in multi-modes using various multimedia sources, and network simultaneously with other web users. In fact, Topacio (2018) contends that "part from technological materials, educators have to take into consideration the role of the Internet, World Wide Web and the social media in educating the youth of today" (p. 87). Therefore, this research adds that students need further development of Internet literacy and constructive development of Chat programs literacy including ethics, symbols and Chat abbreviations and acronyms. Indeed, Murphy and Collins (1997) brought forward some advantages on using Electronic Chats for instructional purposes. Advantages include: "fostering immediacy and social presence, allowing one-to-one advising, presenting timely issues, building a community of learners, and supplementing other forms of communication" (p. 177).

\section{* Encouraging students/learners autonomy}

Topacio (2018) warns that "the lack of learner autonomy skills and overreliance on Internet materials due to convenience may also be seen as impediments for the full success of online learning. Without appropriate learner autonomy skills, students will find it difficult to establish effective study habits and time management as both are important in online-based instruction" (p. 100).

\section{* Training of instructors and teachers in the use of Internet-based instruction}

Finally, the growing acceptance and use of Internet-based instruction implies that instructors/ teachers need to be trained in how to facilitate chatting (Reynard, 2008, para 14) that fosters communication and learning in such settings. Models for interaction analysis of asynchronous computer conferencing should be tested in a synchronous chat environment.

\subsection{Limitations of the Research}

The salient limitation in this study is the small sample size which leads to limit generalization of results and findings. Though the research is exploratory it acts as a major eye-opener to this field of research. Furthermore, the field of using chatting languages is not well researched in the literature one may find few references on distance learning applications as related to English teaching but not in the context of identifying the factors leading to the choice of a language or a mix of languages. Experimental research using role-playing and gaming using chatting to teach 
English also exist MUD's -Multi Users Dimension or Multi Users Dungeons, MOO's -MUD Object Oriented, and MUSE -Multi User Dimension (Nolan and Weiss, 1999). However, one observes here that the use of English is a precondition.

\subsection{Future Research}

This exploratory research paves the way for further development to characterize the sample using a cause-effect quantitative approach to study and identify influencing variables to language use. For example, more attention should be given to identify the factors that influence the attitude of respondents towards selecting the chat language. Another dimension is studying the impact of gender on language selection in chatting. Moreover, performing a cross-sectional country analysis of the same chat habits, that is, selecting several Arab countries and repeating the research. North African countries where bilingual chatters also reside are a good target for comparison.

Another important study that can be conducted in Lebanon is by selecting two well-defined samples of English and French educational institutions and then repeating the experiment.

\section{References}

Al-Haq, F. Al-Abed, \& Al-Sobh, M. A. (2010). The effect of a web-based writing instructional EFL program on enhancing the performance of Jordanian secondary students. The JALT CALL Journal, 6(3), 189-218. https://doi.org/10.29140/jaltcall.v6n3.101

Aljuhani, K. O., Abbas, S. A., \& AbdulAziz, A. (2018). Review of Information Quality of E-learning Systems in Saudi Arabia. International Advanced Research Journal in Science, Engineering and Technology, 5(5), 43-50. Retrieved May 2, 2021, from https://www.researchgate.net/publication/325553519_Review_of_Information_Quality_of_E-learning_Systems _in_Saudi_Arabia

Almeida d'Eça, T. (2002). To chat or not to chat in the EFL classroom, that is the question! Paper presented at the "Language - Communication - Culture" International Conference, University of Évora, Portugal, on November 29, 2002. Retrieved March 21, 2021, from at http://www.malhatlantica.pt/teresadeca/papers/evora2002/chat-and-efl.htm

Almeida d'Eça, T. (2003). The Use of Chat in EFL/ESL. The Electronic Journal for English as a Second Language, 7(1). Retrieved March 17, 2021, from http://www.tesl-ej.org/wordpress/issues/volume7/ej25/ej25int/

Al-Shamat, H. (2009). Educational Divide across Religious Groups in Nineteenth-Centruy Lebanon: Institutional Effects on the Demand for Curricular Modernization. Journal of Islamic Studies, 20(3), 317-351. https://doi.org/10.1093/jis/etp024

Angelo State University (2021). Section 3.2 Online Learning Tools: Synchronous Communication Tools. Retrieved March 1, 2021, from

Bacha, N. N., \& Bahous, R. (2011). Foreign Language Education in Lebanon: A Context of Cultural and Curricular Complexities. Journal of Language Teaching and Research, 2(6), 1320-1328. https://doi.org/10.4304/jltr.2.6.1320-1328

Bagarukayo, E., \& van der. Weide, Th. P. (2012). Interaction with a Digital Learning Environment of a University. Proceedings of the $4^{\text {th }}$ International Conference on Computer Supported Education (CSEDU2012), 16-18th April, Porto, Portugal.

Bagarukayo, E., Mpangwire, V., Kalema, B. M., \& SDIWC Organization (2014). Integrating a Chatting Tool into a Learning Management System. Proceedings of the Third International Conference on Informatics Engineering and Information Science (ICIEIS2014), September, 2014. Lodz University of Technology, Lodz, Poland

Baker, C. (1988). Key Issues in Bilingualism and Bilingual Education. Clevedon (UK): Multilingual Matters Ltd.

Baker, C. (1996). Foundations of bilingual education and bilingualism. Clevedon: Multilingual Matters.

Bakia, M., Shear, L. Yukie, T., \& Lasseter, A. (2012, January). Understanding the Implications of Online Learning for Educational Productivity. Retrieved March 1, 2021, from https://tech.ed.gov/files/2013/10/implications-online-learning.pdf

Baladi, S. S. (2018). Polyglotism and Identity in Modern-Day Lebanon. Lingua Frankly, 4. https://doi.org/10.6017/lf.v4i0.9611

Bates, A. W. (Tony) (2015). Teaching in a Digital Age. Tony Bates Associates Ltd. Retrieved June 2, 2021, from 
https://open.umn.edu/opentextbooks/textbooks/221

Bialystok, E. (2018). Bilingual education for young children: review of the effects and consequences. International journal of bilingual education and bilingualism, 21(6), 666-679.

https://doi.org/10.1080/13670050.2016.1203859

Bloomfield, L. (1933). Language. Holt Rinehart and Winston, New York. (published in 1935 by George Allen and Unwin, London).

Brink, S., Bayard, J., King, D., \& Audet, M. (2012, April). Competencies in Canada in a globalisation context, In Della Chiesa, B., J. Scott and C. Hinton (Eds.), Languages in a Global World: Learning for Better Cultural Understanding, pp. 201-227, OECD Publishing, Paris. https://doi.org/10.1787/9789264123557-17-en

Bularca, M. C. (2020). Online Teaching and Learning in Higher Education during the Coronavirus Pandemic: Students' Perspective. Sustainability, 12, 10367. https://doi.org/10.3390/su122410367

Byloun, H. J. (2015). The Effect of Teaching and Learning in Native and Foreign Language on Students' Conceptual Understanding in Science in a Lebanese Context, (Masters of Arts in Education), School of Arts and Sciences, Lebanese American University.

Chehimi, G. M. (2002). Sociolinguistics and Social Contexts of Language: An Assessment through Chatting On-line, (Master Thesis), School of Education, Lebanese American University.

Chehimi, G. M. (2021). Lebanese Students' Attitudes toward English: An Exploratory Study. English Linguistics Research 10(2), 20-32. https://doi.org/10.5430/elr.v10n2p20

Christakis, N. A. (2010). How is the Internet changing the way you think? Retrieved March 21, 2021, from

Clover, I. (2017). Advantages And Disadvantages of eLearning. Retrieved May 26, 2020, from https://elearningindustry.com/advantages-and-disadvantages-of-elearning

Cole, A., \& Williams, C. (2004). Institutions, identities and lesser-used languages in Wales and Brittany. Regional \& Federal Studies, 14(4), 554-579。 https://doi.org/10.1080/1359756042000315487

Collins, M. P., \& Murphy, K. L. (1997). Development of Communication Conventions in Instructional Electronic Chats. Journal of Distance Education-JDE, 12(1), 177-200.

Coman, C., Tîru, L. G., Mesesan-Schmitz, L., Stanciu, C., Weber, L., \& Lieberman, J. (2003). Strategies for Effective Use of Chat: When, Why, and How to Make It Work TCC 2000 - A Virtual Odyssey: What's Ahead for New Technologies in Learning? Conference held April 12-14, 2000 Hawaii, USA. Retrieved February 21, 2021, from

http://aubreyroderick.weebly.com/uploads/7/7/4/0/7740924/strategies_for_effective_use_of_chat--when_why_and _how_to_make_it_work.pdf

Contact N. (2020, August 4). A new pedagogy is emerging... and online learning is a key contributing factor. Retrieved March 13, 2021, from https://teachonline.ca/sites/default/files/tools-trends/downloads/a_new_pedagogy_is_emerging.pdf

Coupland, J. (2000). Introduction. In J. Coupland (ed.) Small Talk, (pp. 1-25). Harlow: Longman and Pearson Education.

Crystal, D. (1988). The English Language, Harmondsworth, Penguin Books.

Dickey, M.D. (2004). The impact of web-logs (blogs) on student perceptions of isolation and alienation in a web-based distance-learning environment. Open Learning 19(3), 279-291.

https://doi.org/10.1080/0268051042000280138

Dumbaugh, D. (2020, September 9). Revitalizing Classes through Oral Exams. Retrieved March 21, 2021, from https://www.insidehighered.com/advice/2020/09/09/how-use-oral-examinations-revitalize-online-classes-opinio $\mathrm{n}$

e-learners. (2021). What is distance education? Retrieved February 28, 2021, from https://www.elearners.com/education-resources/what-is-distance-education/ Elo, S., \& Helvi, K. (2008). The qualitative content analysis process. Journal of Advanced Nursing, 62(1), 107-115. https://doi.org/10.1111/j.1365-2648.2007.04569.x

Esseili, F. (2017). A sociolinguistic profile of English in Lebanon. World Englishes, 36(4), 684-704. https://doi.org/10.1111/weng.12262 
European Community. (2006, December 30). Communication in the mother tongue. In Recommendation of the European Parliament and of the Council of 18 December 2006 on key competences for lifelong learning. Official Journal of the European Union, (2006/962/EC), L394/10-18. Retrieved March 21, 2021, from http://keyconet.eun.org/mother-tongue\#: :text=the $\% 20$ mother\%20tongue-,Communication $\% 20$ in $\% 20$ the $\% 20 \mathrm{~m}$ other\%20tongue, $\% 2 \mathrm{C} \% 20$ thoughts $\% 2 \mathrm{C} \% 20$ feelings $\% 2 \mathrm{C} \% 20 \mathrm{facts} \% 20$ and

Feldstein, A. P. (April 24, 2009). Analyzing Online Communities: A Narrative Approach. MiT6: Stone and Papyrus, Storage and Transmission. International Conference. April 24-26, 2009. Massachusetts Institute of Technology, Cambridge. Retrieved March 21, 2021, from

https://www.researchgate.net/publication/228422256_Analyzing_Online_Communities_A_Narrative_Approach

Fishman, J. A. (1976). Bilingual Education: An International Sociological Perspective. Rowley, Massachusetts: Newbury House Publishers.

Fornůsková, J. (2011). What can bilingualism do for you? The advantages of bilingual language development, (Master Thesis). Department of Foreign Languages and Translation, Faculty of Humanities and Education, University of Agder, Norway.

Frisbie, C. (2016, April 18). 15 creative ways people relieve stress online. [Blog]. Mashable. Retrieved March 21, 2021, from https://mashable.com/2016/04/18/stress-relief-internet/

Frizler, K. (1995, December 6). The Internet as an Educational tool in ESOL writing Instructions, (Unpublished Master's thesis). San Francisco State University.

Gaith, G. M., \& Shaaban, K. A. (1996). Language in Education Policy and Planning: The Case of Lebanon. Mediterranean Journal of Educational Studies, 1(2), 95-105.

Graddol, D., Leith, D., Swann, J., Martin Rhys, M., \& Gillen, J. (eds.) (2020). Changing English. London: Routledge. https://doi.org/10.4324/9781003060543

Graddol, David, Leith, Dick, \& Swann, Joan (eds.) (1996). English History, Diversity and Change. (English Language Past, Present and Future). London: Routledge/Milton Keynes, the Open University.

Graziadei, W. D., Gallagher, S., Brown, R. N., \& Sasiadek, J. (1997). Building Asynchronous and Synchronous Teaching-Learning Environments: Exploring a Course/Classroom Management System Solution. Retrieved June 8, 2021, from https://files.eric.ed.gov/fulltext/ED405842.pdf

Grosjean, F. (1999). Individual bilingualism. In Spolsky, B. (Ed.). Concise Encyclopedia of Educational Linguistics. Oxford: Elsevier.

Gumperz, J. J. (1982). Discourse Strategies. (Studies in International Linguistics). Cambridge University Press. https://doi.org/10.1017/CBO9780511611834

Gupta, S. (2017). 9 Benefits of eLearning for Students. Retrieved May 26, 2020, from https://elearningindustry.com/9-benefits-of-elearning-for-students

Gustafsson, J. (2012, June 13). In the mix: Linguistic mélange bi Lubnan [Blog]. Mashallah News. Retrieved May 13, 2021, from https://www.mashallahnews.com/language-mix-in-lebanon/

Hakuta, K. (Spring 1990). Bilingualism and Bilingual Education: A Research Perspective. National Clearinghouse for Bilingual Education (NCBE). Electronic Journal, NCBE FOCUS: Center for Applied Linguistics. George Washington University. Occasional papers in Bilingual Education, No.1. Retrieved May 2, 2021, from https://files.eric.ed.gov/fulltext/ED321584.pdf

Harasim, L. (2012). Learning Theory and Online Technologies. New York/London: Routledge. https://doi.org/10.4324/9780203846933

Harris, I. (2019, December 17). Code-Switching Is Not Trying to Fit in to White Culture, It's Surviving It [Blog]. Retrieved March 21, 2021, from https://www.yesmagazine.org/opinion/2019/12/17/culture-code-switching

Haugen, E. (1956). Bilingualism in the Americas: A Bibliography and Research Guide, Alabama: Alabama University Press.

Hejase, A. J., \& Hejase, H. J. (2013). Research methods: A practical approach for business students (2nd Edition). Philadelphia, PA, USA: Masadir Inc.272.

Hejase, H. J. (2000). Learning Through Chatting. Proceedings of the -Discovering Connections $\|$ Conference, September 24-27. The University of Michigan -Dearborn, Michigan, USA. 
Hejase, H. J. (January 14-16, 2004). Chatting as a tool for research in management topics. Proceedings of the 25th McMaster World Congress: Management of Electronic Business. Hamilton, Ontario - Canada .

Hejase, H. J., \& Chehimi, G. M. (2020). E-learning: What to look for amid the pandemic. Journal of Economics and Economic Education Research, 21(Special Issue 1), 1-4. https://doi.org/10.13140/RG.2.2.17011.35369

Hejase, H. J., Hejase, A. J., \& Khatib, I. (2013). Seeking Expert Opinion Online: An Exploratory Research. International J. Soc. Sci. \& Education, 3(2), 240-263.

Henshilwood, C. S., \& Dubreuil, B. (2009). Reading the artefacts: gleaning language skills from the Middle Stone Age in southern Africa. Cradle Language, 2, 61-92.

Henshilwood, C. S., d'Errico, F., Yates, R., Jacobs, Z., Tribolo, C., Duller, G. A., et al. (2002). Emergence of modern human behavior: Middle Stone Age engravings from South Africa. Science, 295(5558), 1278-80. https://doi.org/10.1126/science.1067575

Hodeib, M. (2007, January 19). English assumes greater importance in Lebanese linguistic universe. Daily Star: Lebanon News. Retrieved May 1, 2021, from

https://www.dailystar.com.lb/News/Lebanon-News/2007/Jan-19/45910-english-assumes-greater-importance-in-1 ebanese-linguistic-universe.ashx

Hodson, R. F. (1998), =Merging asynchronous and synchronous learning networks with Web 4-M. Asynchronous Learning Networks (ALN), 2(2), p. 2.

Hornberger, N. (1991). Extending enrichment bilingual education: revisiting typologies and redirecting policy. In O. Garcia (ed.). Focus on Bilingual Education Essays in honor of Joshua A. Fishman, (pp. 215-238). John Benjamins Publishing Company. https://doi.org/10.1075/z.fishfest1.19hor

Hrastinski, S. (2008, November 17). Asynchronous and Synchronous E-Learning. Retrieved March 21, 2021, from https://er.educause.edu/articles/2008/11/asynchronous-and-synchronous-elearning

Hudak, P. L., \& Maynard, D. W. (2011). An interactional approach to conceptualising small talk in medical interactions. Sociology of health \& illness, 33(4), 634-653. https://doi.org/10.1111/j.1467-9566.2011.01343.x

Institute of Lebanese Language. (2010, February $2^{\text {nd }}$ ). Numbers in Words! [Blog]. Institute of Lebanese Language. Retrieved March 21, 2021, from http://www.lebaneselanguage.org/blog/numbers-in-words/

Johnstone, D. B. (1992). Learning Productivity: A New Imperative for American Higher Education, (Monograph). Studies in Public Higher Education, The State University of New York.

Jukes, I., McCain, T., \& Crockett, L. (2010). Understanding the digital generation: Teaching and learning in the new digital landscape. Century Fluency Project: Canada.

Khoury, A. H., Nasir Eddeen, L. M., Saadeh, D. S., \& Harfoushi, O. K. (2011). E-learning: Justification and Obstacles. International Journal of Emerging Technologies in Learning, 6(3), 53-56. https://doi.org/10.3991/ijet.v6i3.1610

Krishnan, K., \& Rogers, S. P. (2015a). Social Platforms. In Social Data Analytics: Collaboration for the Enterprise, (pp. 75-91). MK Series on Business Intelligence: Elsevier Inc. Retrieved June 5, 2021, from https://www.sciencedirect.com/topics/computer-science/discussion-forum

Krishnan, K., \& Rogers, S. P. (2015b). Social Platforms. In Social Data Analytics:

Landow, G. L. (1992). Hypertext, The convergence of contemporary critical theory and technology. Baltimore: Johns Hopkins University Press

Larousse. (n.d.). Emprunt. In Larousse.fr dictionary. Retrieved June 10, 2021, from https://www.larousse.fr/dictionnaires/francais/emprunt/29014

Laudon, K.C. \& Laudon, J.P. (2010). Management Information Systems: Managing the Digital Firm, $11^{\text {th }}$ edition, New Jersey: Pearson/Prentice Hall.

Leiner, B. M., Cerf, V. G., Clark, D. D., Kahn, R. E., Kleinrock, L., Lynch, D. C., Postel, J., Roberts, L. G., \& Wolff, S. (1997). Internet Society. Retrieved March 21, 2021, from https://www.internetsociety.org/internet/history-internet/brief-history-internet/

Leonardi, M. M. V. (2016, September). Bilingualism or Trilingualism? Social versus linguistic views: Evidence from the Germanic-speaking language group in South Tyrol (Italy). (PhD Dissertation in Bilingualism), School of 
Linguistics \& English Language, Bangor University. Retrieved May 12, 2021, from https://core.ac.uk/download/pdf/228925572.pdf

Little, A. (2018, June 6). Scotland and Britain 'cannot be mistaken for each other'. BBC News. Retrieved May 10, 2021, from https://www.bbc.com/news/uk-scotland-44361867

Liu, G. Z. (1999). Virtual Community Presence in Internet Relay Chatting, Journal of Computer-Mediated Communication, 5(1), JCMC514, https://doi.org/10.1111/j.1083-6101.1999.tb00334.x

Lyness, D'A. (2018, January). Talking About Your Feelings [Blog]. Retrieved June 2, 2021, from https://kidshealth.org/en/kids/talk-feelings.html

Mackey, W. F. (1962). The Description of Bilingualism. Canadian Journal of Linguistics, 7, 51-85. https://doi.org/10.1017/S0008413100019393

Mackey, W. F. (1968). The Typology, Classification and Analysis of Language Tests. Language Learning, 18(S3), 163-166. https://doi.org/10.1111/j.1467-1770.1968.tb00229.x

MacNamara, J. (1969). How can one measure the extent of a person's bilingual proficiency? In Kelly 1969, pp. 79-97.

Marot, B. (2018). Developing post-war Beirut (1990-2016): The political economy of "pegged urbanization." (PhD Dissertation). School of Urban Planning, McGill University, Montreal, Canada. Retrieved May 17, 2021, from https://halshs.archives-ouvertes.fr/tel-03099844/document

Merriam-Webster. (n.d.). Bilingualism. In Merriam-Webster.com dictionary. Retrieved April 20, 2021, from https://www.merriam-webster.com/dictionary/bilingualism

Meyen, E. L., Aust, R. J., Bui, Y. N., \& Isaacson, R. (2002). Assessing and monitoring student progress in an e-learning personnel preparation environment. Teacher education and special education, 25 (2). 187-198. https://doi.org/10.1177/088840640202500210

Moradi, H. (2014, September). An Investigation through Different Types of Bilinguals and Bilingualism. International Journal of Humanities \& Social Science Studies (IJHSSS), I(II), 107-112.

Neuage, T. (2004). Conversational analysis of chatroom talk. Retrieved June 12, 2021, from https://citeseerx.ist.psu.edu/viewdoc/download?doi=10.1.1.114.633\&rep=rep1\&type=pdf

Ng, S. H., \& Bradac, J. J. (1993). Power in language: verbal communication and social influence. Newbury Park: Sage Publications. http://www.loc.gov/catdir/enhancements/fy0655/93018762-t.html

Pappas, Christopher (2015, November 14). Synchronous Learning Advantages and Disadvantages in Corporate Training $\quad[\mathrm{B} \log ]$ Retrieved March 21, 2021, from https://elearningindustry.com/synchronous-learning-advantages-and-disadvantages-in-corporate-training

Penninx, R. (2019). Problems of and solutions for the study of immigrant integration. Comparative Migration Studies-CMS, 7(13), 1-11. https://doi.org/10.1186/s40878-019-0122-х

PEW Research. (2004, September 1). How Americans Use Instant Messaging [Blog]. Retrieved May 27, 2021, from https://www.pewresearch.org/internet/2004/09/01/how-americans-use-instant-messaging/

Pew, R. (2015). Influence of Internet in Emerging and Developing Nations. Retrieved March 21, 2021, from

Poplack, S. (1980). Sometimes I'll start a sentence in Spanish Y TERMINO EN ESPANOL: Toward a typology of code-switching. Linguistics, 18(7/8), 581-618. https://doi.org/10.1515/ling.1980.18.7-8.581

Reynard, Ruth (2008, January 16). Tips for Using Chat as an Instructional Tool [Blog] The Journal.com. Retrieved May 23, 2021, from https://thejournal.com/articles/2008/01/16/tips-for-using-chat-as-an-instructional-tool.aspx

Robertson, K. (2014, December 6). Five Things Teachers Can Do to Improve Learning for ELLs in the New Year [Blog]. $\quad$ Retrieved $\quad$ June $2021, \quad$ from https://www.colorincolorado.org/article/five-things-teachers-can-do-improve-learning-ells-new-year

Robinson, W. P. (1972). Language \& Social Behaviour. Harmondsworth: Penguin.

Robles, M., \& Braathen, S. (2002). Online assessment techniques. Delta Pi Epsilon Journal, 44 (1). 39-49.

Romaine, S. (1989). Bilingualism. Oxford: Basil Blackwell Publishers

Romaine, S. (1998). Bilingualism. Oxford: Blackwell Publishers Inc. 
Rovai, A. P. (2000). Online and traditional assessments: what's the difference? Internet and higher education, 3, 141-151. https://doi.org/10.1016/S1096-7516(01)00028-8

Russell, G. (2021). Absence of Face-to-Face Communication is One of the Benefits of Online Learning [Blog].

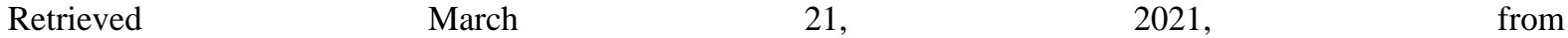
https://blog.online.colostate.edu/blog/uncategorized/absence-of-face-to-face-communication-is-one-of-the-bene fits-of-online-learning/

Sayigh, R. (1965). The Bilingualism Controversy in Lebanon. The World Today, 21(3), 120-130. Retrieved May 17, 2021, from http://www.jstor.org/stable/40393712

Shaaban, K. (2017). The ongoing rivalry between English and French in Lebanon. In Atta Gebril (Ed.). Applied Linguistics in the Middle East and North Africa: Current practices and future directions, pp. 162-182. John Benjamins Publishing Co. https://doi.org/10.1075/aals.15.07sha

Shawish, H. (2010, June 24). Campaign to save the Arabic language in Lebanon. BBC News, Beirut. Retrieved May 10, 2021, from https://www.bbc.com/news/10316914

Shirley, Emma (2016, April). Societal Bilingualism and Language Attitude Trends in Catalonia and Brussels-Capital Region, (Master Dissertation). Department of European Languages and Cultures, Lancaster University.

Singh, J. (n.d.). Chapter 7 - Chat, Messaging and forums. Retrieved March 12, 2021, from https://danielneis.github.io/how-to-use-moodle-27/chapter7.html

Sipe-Haesemeyer, M. A. (2005). Bringing the World Wide Web into Third World Countries: Integrating Technology Across the Globe. Global Media Journal, 4. Retrieved March 21, 2021, from https:/www.globalmediajournal.com/open-access/bringing-the-world-wide-web-into-third-world-countries-inte grating-technology-across-the-globe.php?aid=35133

Smith, Aaron, \& Anderson, Monica (2018, March 1). Social Media Use in 2018. Pew Research Center. Retrieved March 21, 2021, from https://www.pewresearch.org/internet/2018/03/01/social-media-use-in-2018/

Smutny, P., \& Schreiberova, P. (2020, July). Chatbots for learning: A review of educational chatbots for the Facebook Messenger. Computers \& Education, 151, 1-11. https://doi.org/10.1016/j.compedu.2020.103862

Stroud, C. (2002). Towards a Policy for Bilingual Education in Developing Countries. New Education Division Documents No. 10. Swedish International Development Cooperation Agency, Stockholm, Sweden. Retrieved April 20, 2021, from

https://publikationer.sida.se/contentassets/4dd1745d0376402bb3714f10dfa8efe0/towards-a-policy-for-bilingualeducation-in-developing-countries_622.pdf

Talk in Arabic. (2021). Transliteration and texting in Arabic - Why so many numbers? Retrieved March 21, 2021, from https://www.talkinarabic.com/arabic-texting/

Thonhauser, I. (2000). Multilingual Education in Lebanon: 'Arabinglizi' and Other Challenges of Multilingualism. Mediterranean Journal of Educational Studies, 6(1), 49-61.

Thurlow, C., Lengel, L., \& Tomic, A. (2004). Computer mediated communication. Thousand Oaks, CA: Sage.

Tohme, S. (2019, August). Langauge Creativity: A Socioliguistic Reading of Linguistic Change in Lebanon. BAU Journal - Society, Culture and Human Behavior, 1(1), Article 2. Retrieved May 11, 2021, from https://digitalcommons.bau.edu.lb/schbjournal/vol1/iss $1 / 2$

Topacio, K. N. M. (2018). Exploring the use of online educational platform in teaching writing among ESL students. Journal of Language and Linguistic Studies, 14(21), 86-101.

Twigg, C. A. (1992). Improving Productivity in Higher Education: The Need for a Paradigm Shift. CAUSE/EFFECT, $15(2), 39-45$.

Waddell, K. (2017, November 20, 2017). Mapping the Blurred Lines of Beirut's Languages [Blog]. Bloomberg CityLab. Retrieved March 21, 2021, from

https://www.bloomberg.com/news/articles/2017-11-20/mapping-the-many-languages-of-beirut

Weber, L., \& Lieberman, J. (2000). Strategies for Effective Use of Chat: When, Why, and How to Make It Work. Retrieved March 21, 2021, from http://aubreyroderick.weebly.com/uploads/7/7/4/0/7740924/strategies_for_effective_use_of_chat--when_why_a nd_how_to_make_it_work.pdf 
Weber, L., \& Lieberman, J. (2003). Strategies for Effective Use of Chat: When, Why, and How to Make It Work TCC 2000 - A Virtual Odyssey: What's Ahead for New Technologies in Learning? Conference held April 12-14, 2000 Hawaii, USA. Retrieved February 21, 2021, from http://aubreyroderick.weebly.com/uploads/7/7/4/0/7740924/strategies_for_effective_use_of_chat--when_why_a nd_how_to_make_it_work.pdf

Wei, L. (2000). Dimensions of bilingualism. In: Wei L, editor. The bilingualism reader, (pp. 3-25). New York: Routledge. https://doi.org/10.4324/9781003060406-2

Weinreich, U. (1968). Languages in contact: Findings and problems. The Hague: Mouton.

Wiklund, M. (2018). Indicating Dependency between Spoken Sentences by Prosodic Means. Discours. https://doi.org/10.4000/discours. 9675

Wil (2017). English became global language [Blog]. EF English Live. Retrieved March 21, 2021, from https://englishlive.ef.com/blog/english-in-the-real-world/english-became-global-language/

Womack, D. F. (2012). Lubnani, Libanais, Lebanese: Missionary Education, Language Policy and Identity Formation in Modern Lebanon. Studies in World Christianity, 18(1), 4-20. https://doi.org/10.3366/swc.2012.0003

Zazulak, S. (2015, August 21). English: the language of the internet [Blog]. Pearson. Retrieved March 21, 2021, from https://www.english.com/blog/english-language-internet/ 


\section{Appendix A}

Table A. Exhibits of chatting

\begin{tabular}{l} 
Chat: Writing Arabic with English letters \\
\hline February 10, 2019, 8:00 PM \\
Student Full Name [Removed for confidentiality] \\
X sent \\
How r u? \\
Dr iza ma sadda2na our university degree bi wazarit el \\
tarbiya chou bi sir?
\end{tabular}

February 11, 2019, 4:35 PM

You sent February 11, 2019

Usually you need it done when papers are asked for in a job

You sent February 11, 2019

It is better to have them ready always.

2/11/19, 5:50 PM

X sent February 11, 2019

Iza ma baddeh etwazzaf . Daroureh a3melon?

I mean ma32oul my degree tou3tabar melghiyyeh iza ma bsadde2a bel wazara?

\section{Chat: Using numbers to express Arabic letters with difficult} sounds... See Table 8

January 3, 2019

Students Full Name [Removed for confidentiality]

Y sent

Laaaa ma 3m ed7ak 3 7ada!!

Y sent January 3, 2019

\section{Le btfhmne 8lt!}

Z sent January 3, 2019

The way you commented means that. And many are getting angrier.

You sent January 3, 2019

Anyway, we can talk tomorrow about such an issue.

Z sent January 3, 2019

I am reading along many people's comments, and things are bad. The problem many of your friends or others are using the same style.

Z sent January 3, 2019

This is not acceptable.

Y sent January 3, 2019

La Imwdou3 mish m7rez n7ki fi w ma asde etms5r 3 7ada
Dr. if we did not seek government attestation of our university degree in the Ministry of Education what happens?

If I do not want to be employed, is it necessary to do attestation?

I mean, is it possible that my degree is considered nullified if we do not want to attest in the Ministry?

No, I am not laughing at anybody!!

Why you understand me wrong! 
Z sent January 3, 2019

Rewrite in English.

Y sent January 3, 2019

\section{Bs edeya2 ma b3rf e7ki english}

Y sent January 3, 2019

5er b3tzer eza deya2et

Z sent January 3, 2019

Then we will talk tomorrow.

Y sent January 3, 2019

Bs akid ma b2sod enne hen 7ada 2w 2alel min 2emet 7ada

Z sent January 3, 2019

Have a good night.

Y sent January 3, 2019

U 2

\section{Chat: Using English and Arabic}

January 13, 2019, 7:35 PM

Y sent January 13, 2019

Salam. I want to apologize about my words in the last Discussion. I have a problem in my life that affected me in negative way. I am trying to forget and be nice with the others but it will take time

Y sent January 13, 2019

Please forgive me and try to assess my situation

هرهه هيدا لطلع معي انشالله ما يكون في غلط

Z sent January 13, 2019

Hi. No worry, I am not angry. You are forgiven.

Z sent January 13, 2019

Try to write always like that.

Chat: Using Arabic, Arabic written with English letter, English and French

June 16, 2019, 1:08 PM

$\mathrm{X}$ sent

$\mathrm{Hi}$
The subject is not worth to talk about it and I do not mean to mock at anyone

When I feel uncomfortable I do not know to talk in English

Good, I apologize if I make you upset

But I assure that I do not mean to insult anyone or undermine the value of anyone
Using Arabic Fully:

Hehehehe...This is what I got, God Willing there are no mistakes 
Y sent June 16, 2019

$\mathrm{Hi}$

X sent June 16, 2019

How r u ?

Y sent June 16, 2019

Fine and $u$ ?

X sent June 16, 2019

Im fine too

Y sent June 16, 2019

So, interview with who?

X sent June 16, 2019

With a stupid woman

Swarovski

Y sent June 16, 2019

Come on!!

X sent June 16, 2019

She didnt tell me her name!!!!

Y sent June 16, 2019

So

X sent June 16, 2019

so when $i$ asked her she gazed at me inno ya latif ka2enna general aoun i should know her!!!

So when i asked her she gazed at me [as if, Oh God have mercy, personalizing General Aoun] I should know her.

Y sent June 16, 2019

And

X sent June 16, 2019

\section{Ttalla3it fiyeh bel eleb}

Ma eblouneh bel job... ils m'ont rejeté

So is it bad to ask ur interviewer name?

She looked at me with a wrong face (using Lebanese jargon ... giving a wrong face!)

They did not accept me for the job... [then using French]... They rejected me

Y sent June 16, 2019

Not really. But usually this is not the point.

X sent June 16, 2019

8 hours $700 \$$ sales in abc ashrafieh 
She wanted someone with experience

But she told me i will do a training for three days, tsawar!

But then she didnt call me ba2...merde

X sent June 16, 2019

Another interview with other company she didnt tell me the salary

She said we will call $u$ for interview with finance manager the position is his assistant, m3qool! Uff...shu haida

X sent June 16, 2019

So i didnt go

\section{I dont want to work tete a tete with him}

Im not looking for job now

Y sent June 16, 2019

Need to do something or go to training

X sent June 16, 2019

\section{Ma fhemet}

Y sent June 16, 2019

You need to start working even with low salary, then opportunities will come more

X sent June 16, 2019

Ok

Y sent June 16, 2019

When interviews are offered, should not resist.

X sent June 16, 2019

They $r$ not taking me either the work is unsuitable. Ana mosh 5admeh!! يعني معقول هيك

Y sent June 16, 2019

a little bit about interviews and what to ask and what not!

Nzale 3an el berj ya helweh

ما تشوفي حالك

X sent June 16, 2019
English letters)

Using mix of three languages: But she did not call me [English] ... then using Lebanese jargon word to mean stop using Arabic written with English letters... then using the French word for Shit.

Is this possible!!![m3qool!]; Word to show protest [Uff]... then What is this!!

Mix English-French [tete a tete]

I did not understand

Mix of English + Arabic with numbers using English letters ( I am not a servant)+ Arabic (Meaning... Is it possible this way)

Jargon Arabic for using Google [Gawgle]

Arabic with number and English letters: Come down from your tower beauty!!!

Arabic: Do not show off 
Loooool... I dont want to work with a man all day!

Good idea

But she shoukd have presented herself!! شايفي حالها

Y sent June 16, 2019

If a man is expert, you learn from him

X sent June 16, 2019

$\mathrm{Mmm}$

Y sent June 16, 2019

Also, try to continue your preparations, many certificates are there.

X sent June 16, 2019

Lachou! Ma bi fido... Waste of time!!

Y sent June 16, 2019

Certificates are technical!! Walaow!! Ma bi fido!! Ufff Minnik... ignorante (:)

X sent June 16, 2019

Loooooool...Mmm.... Bass I like psychology

If $i$ wanna study i like to study it

Y sent Junr 16, 2019

You need to either strengthen your knowledge in your field or you have to switch careers!!
Arabic: She is showing off!!!

What for, these have no benefit... Waste of time

Mix English [Certificates are technical!!] + Arabic [Walaow!! Ma bi fido!! Ufff Minnik... meaning: Come on!! Not beneficial!! I am fed up with you] + French [ignorante $($ ()) $=$ Ignorant + Smiley]

\section{Copyrights}

Copyright for this article is retained by the author(s), with first publication rights granted to the journal.

This is an open-access article distributed under the terms and conditions of the Creative Commons Attribution license (http://creativecommons.org/licenses/by/4.0/). 